\title{
¿ACTOS PREPARATORIOS O PRE-CRÍMENES? ¿PENAS O PRE-CASTIGOS? APROXIMACIÓN AL FUNDAMENTO DE LA CRIMINALIZACIÓN DE LA PREPARACIÓN DELICTIVA*
}

\begin{abstract}
Alberto Alonso Rimo**
Resumen: El trabajo se orienta a mostrar que buena parte de los tipos preparatorios vigentes constituyen manifestaciones de un Derecho penal de autor y a llamar la atención sobre los serios peligros que ello implica desde la perspectiva de los principios dimanantes de un Estado democrático de Derecho. A tal efecto, se parte principalmente del ejemplo del derecho positivo español pero se alude también a la experiencia angloamericana, que refleja de manera particularmente expresiva la evolución del Derecho penal contemporáneo hacia un modelo puramente preventivo y de la peligrosidad, y se examina asimismo la regulación italiana como exponente de dicho paradigma. En la última parte del estudio se explica cuál es la justificación que, a fin de conjurar

Recibido: julio 2018. Aceptado: octubre 2018

* Este trabajo se ha realizado en el marco del proyecto de I + D + I DER201677947-R (AEI/FEDER, UE), financiado por el Ministerio de Ciencia, Innovación y Universidades.

** Profesor Titular de Derecho Penal. ORCID ID: 0000-0002-1091-5269

Departamento de Derecho penal. Facultad de Derecho de la Universidad de Valencia. Avd. de los naranjos s/n. 46022 Valencia. E-mail: alberto.alonso@ uv.es
\end{abstract}


aquellos riesgos, considera el autor que habría de regir el castigo de los actos preparatorios en un sistema democrático y, al hilo de ello, se realizan algunas consideraciones sobre el contenido a otorgar, desde ese mismo prisma, al principio del hecho.

Palabras clave: actos preparatorios, Derecho penal de la peligrosidad, Derecho penal de autor, principio del hecho, medidas de seguridad.

\title{
PREPARATORY ACTS OR PRE-CRIMES? PENALTIES OR \\ PRE-PUNISHMENTS? AN EXAMINATION OF THE RATIONALE \\ BEHIND THE CRIMINALISATION OF ACTS PREPARATORY \\ TO AN OFFENCE
}

\begin{abstract}
The aim of the present study is, firstly, to demonstrate that the penalising of many of the preparatory offences included in our legislation is based on the dangerousness of the actor rather than on his or her specific acts (actor-based criminal law). Secondly, it seeks to draw attention to the serious dangers which this criminal law paradigm raises for the principles underpinning a democratic state governed by the rule of law. While the analysis will be based principally on the example of Spanish positive law, it will also draw on the Anglo-American experience, which offers a particularly expressive example of the evolution of contemporary criminal law towards a purely preventive model, and it will also consider Italian legislation. The last part of the study explores the rationale to be given for punishing acts preparatory to an offence in a democratic system and, in doing so, some considerations are made about the content to be granted to the act requirement in this context.
\end{abstract}

Keywords: acts preparatory to an offence, dangerousness criminal law, actor-based criminal law, act requirement, security measures.

\section{Delitos de preparación y Derecho penal de autor}

En un trabajo anterior me preguntaba, con ocasión del análisis de la regulación de los tipos preparatorios de la Parte Especial, si un número considerable de esas figuras no admitirían verse como manifestaciones de un Derecho penal de autor ${ }^{1}$.

1 ALONSO RIMO, A., “¿Impunidad general de los actos preparatorios? La expansión de los delitos de preparación”, en InDret. Revista para el análisis del Derecho, 4, 2017, p. 64. 
En estos momentos me atrevería a elevar dichas sospechas a la condición de conclusiones definitivas. Dedicaré la primera parte del artículo a justificar esta afirmación ${ }^{2}$.

Antes que cualquier otra cosa conviene destacar que el vínculo entre punición de actos preparatorios y Derecho penal de autor no resulta en absoluto novedoso. La doctrina lo ha puesto tradicionalmente de manifiesto subrayando que se trata de comportamientos que pertenecen a estadios tempranos del iter criminis, previos en todo caso al inicio de la ejecución delictiva y que se sitúan, por consiguiente, en los aledaños de la llamada fase interna, en la que se integran ya las resoluciones de la voluntad y el pensamiento ${ }^{3}$. En este sentido cabe asimismo aducir la tantas veces señalada constatación histórica de que las regulaciones que incriminan con mayor amplitud la preparación del delito se corresponden con regímenes políticos de corte autoritario ${ }^{4}$, proclives por tanto a la criminalización de la disidencia ideológica y en los que la lucha contra la delincuencia no se detiene ante los límites que representan los derechos individuales y las garantías

2 Algo que en su momento no pude hacer, dado que el objetivo de esa otra investigación residía en analizar el concepto de acto y delito preparatorio y, a partir de ahí, en verificar la extensión alcanzada por tales figuras en nuestro ordenamiento, como paso previo, precisamente, al cometido de examinar el fundamento de su castigo (lo que es objeto del presente trabajo).

3 Vid. RODRÍGUEZ MOURULLO, G., "La punición de los actos preparatorios", en Anuario de Derecho Penal y Ciencias Penales, 21-2, 1968 pp. 288-292, aduciendo, en referencia a la incriminación genérica de la conspiración, la proposición y la provocación, que la esfera de lo punible comienza entonces mucho antes del inicio de la ejecución del delito, antes incluso de su mera preparación material, y con ello se inserta en el proceso evolutivo que conduce de un Derecho penal del acto a un Derecho penal de autor. Cfr. también ORTS BERENGUER, E., "Consideraciones sobre la fase interna y los actos preparatorios del delito", en Cuadernos de Política Criminal, 18, 1982, pp. 486 y 491; o MUÑAGORRI LAGUÍA, I., "Punición o despenalización de la proposición para delinquir", en Anuario de Derecho penal y Ciencias penales, T. 42, Fasc. 3, 1989, p. 997, citando a ROXIN, ARTZ y TIEDEMANN: cuanto más se adelanta el momento del castigo más se desplaza éste al momento de las meras ideas y reflexiones.

4 JIMÉNEZ DE ASÚA, L., La ley y el delito, Losada, Buenos Aires, 1954, p. 502. 
liberales, entre las que se cuenta, sin duda y en primera línea, el principio del hecho. El deslizamiento hacia un Derecho penal de autor constituye pues, indudablemente, un riesgo inherente a la criminalización de actos preparatorios. Lo que no quiere decir, como veremos, que tal criminalización en abstracto -al margen de cuál sea su específica regulación-resulte en todo caso incompatible con el principio del hecho.

Un segundo aspecto que procede asimismo resaltar en este contexto es el siguiente: se suele ligar la sanción restrictiva de los actos preparatorios con fundamentaciones de su prohibición de carácter objetivo, basadas en la amenaza que aquellos representan para el bien jurídico del delito-fin, mientras que a las teorías subjetivas, que cifran la justificación del castigo en la contrariedad a Derecho de la voluntad manifestada a través de tales comportamientos, se asocia un margen de tipificación de los mismos mucho mayor ${ }^{5}$. Ello tiene todo el sentido. Desde la perspectiva subjetiva, en tanto que el acto preparatorio implica la manifestación de una voluntad criminal exteriorizada, no habría razón, en puridad, para mantener su impunidad en ningún caso; esto es, asumiendo tal concepción hasta sus últimas consecuencias lo coherente sería postular el principio de punición general de los actos preparatorios ${ }^{6}$. Por el contrario, y esto es lo

5 Vid., por ejemplo, DÍAZ Y GARCÍA CONLLEDO, M., "Conspiración, proposición y provocación”, en LUZÓN PEÑA (dir.), Enciclopedia Penal Básica, Comares, Granada, 2002, p. 301; BUSTOS RAMÍREZ, J., Lecciones de Derecho penal. Parte General, Trotta, Madrid, 2006, pp. 374-376.

6 Para las llamadas teorías mixtas (o de la impresión), el fundamento de la incriminación de los actos previos a la consumación se halla en la exteriorización de una voluntad delictiva, de igual modo que sucede en las teorías subjetivas, si bien aquí se aspira a limitar el resultado generalizador del castigo de tales comportamientos, al que conduce el señalado punto de partida, requiriendo añadidamente el requisito -en teoría, objetivo- de generación por el hecho de un cierto grado de conmoción en la colectividad. Con todo, dado el presupuesto de la punición -la mera manifestación de una voluntad contraria a Derecho- y la imprecisión del criterio corrector (la conmoción social creada), el potencial expansivo de la criminalización de los actos preparatorios sigue siendo también en este caso mayor que en el de las tesis objetivas. 
que ahora interesa principalmente destacar, si se vincula el fundamento de su sanción a la existencia de un peligro más o menos relevante para el bien jurídico, en la línea de las tesis objetivas, y dado que hablamos de conductas que por definición resultan anteriores al comienzo de la ejecución del delito, y bastante lejanas por tanto -en general- a la lesión del bien jurídico, el ámbito de vigencia de los tipos preparatorios habría de resultar en principio mucho más reducido ${ }^{7}$.

De acuerdo con esto último, habida cuenta del elevado número de delitos de preparación existente en el ordenamiento penal español -lo que revela que nuestro sistema de incriminación de los actos preparatorios es en realidad mucho más extenso del que a primera vista, o a la vista de la regulación de la cuestión en la Parte General del Código penal, podría parecer $^{8}$ - cabría cuestionar ya de entrada, siquiera sea indiciariamente, que la justificación del castigo de los actos preparatorios en nuestro Código penal obedezca, al menos en su totalidad, a consideraciones relacionadas con la ofensa al bien jurídico y no a concepciones de índole subjetiva, que entroncarían con un Derecho penal de la voluntad y de autor.

Esta idea resulta reforzada si se comprueba de manera específica la escasa lesividad de muchos de esos supuestos típicos. Como ya expuse en otro lugar, en nuestro Código penal el

7 Para JAKOBS (“Criminalización en el estado previo a la lesión de un bien jurídico", trad. Peñaranda Ramos, en EL MISMO, Estudios de Derecho penal, Civitas, Madrid, 1997, p. 295), no obstante, la referencia del bien jurídico no posee ninguna virtualidad restrictiva y conduce a legitimar el castigo de las anticipaciones de la punibilidad sin limitación alguna. Vid. lo observado a este respecto infra: nota 88 .

8 En los últimos tiempos asistimos, en efecto, a una notable y desordenada proliferación de tipos preparatorios vía Parte Especial, que se extiende, casi a modo de plaga, ante la mirada en muchos casos indolente de la doctrina $\mathrm{y}$ ante una jurisprudencia proclive en términos generales a su aplicación. A partir de esta constatación creo que se debe relativizar en buena medida la excepcionalidad del castigo de los actos preparatorios en nuestro ordenamiento penal. Vid. extensamente sobre ello, ALONSO RIMO, A., “iImpunidad general...", cit., pp. 47 y ss. 
castigo de la preparación delictiva se prevé no pocas veces en relación con casos que constituyen ya en sí mismos hipótesis de tutela penal adelantada -0 , incluso, muy adelantada- (anticipación de la anticipación), como, por ejemplo, los delitos de clima $^{9}$ o de pertenencia ${ }^{10}$. La criminalización de la preparación de la preparación, en esa misma línea, es un fenómeno que cobra una amplitud considerable en nuestro derecho vigente -en un sentido extensivo e intensivo, pues los términos en que está prevista la regulación invitan a castigar la preparación en bucle-; y no sólo respecto de delitos-fin graves, como los de terrorismo ${ }^{11}$, sino también de menor trascendencia ${ }^{12}$. Estamos, en suma, ante actuaciones muy prematuras, muy lejanas todavía al momento del daño al bien jurídico, que representan en todo caso un peligro mediato y que exigen, por tanto, necesariamente una o varias actuaciones ulteriores antes de que se pueda alcanzar tal lesión ${ }^{13}$.

Lo que en estos momentos me interesa subrayar es que la más que dudosa ofensividad de muchas de esas figuras previstas en nuestra legislación penal permite pensar que en ellas concurren otro tipo de razones justificadoras del castigo, ajenas a la ilicitud de la conducta concreta, de tal modo que ésta se acaba convirtiendo en un pretexto para sancionar algo distinto; o, expresado de otra forma: que se trata de hipótesis en las que el fundamento de la responsabilidad penal no reside en el concreto

9 Art. 510.1.b) en relación con el art. 510.1.a) CP.

10 Art. 575.1 o 578 , entre otras posibilidades, en relación con el art. 572 CP.

11 Un ejemplo, entre otros muchos posibles: cabría castigar a quien propusiera a otro viajar a una zona bajo control terrorista con el objetivo de adiestrarse para cometer un ulterior delito de terrorismo - preparación de la preparación de la preparación- (arts. 579.3 en relación con el art. 575.1 CP y con cualquiera de los ilícitos previstos en el Capítulo VII del Título XXII del Libro II del Código penal).

12 En el ámbito de las falsedades, por ejemplo, se podría llegar a sancionar la tenencia o fabricación de recipientes orientada a la tenencia (acumulación oculta) de moneda falsa para finalmente realizar el delito-fin de distribución de la moneda falsa (art. 400 en relación con el art. 386.2 CP).

13 Vid. sobre lo anterior, con detalle, ALONSO RIMO, A., “¿Impunidad general...", cit., pp. 56 y ss. 
hecho delictivo ya cometido. Así las cosas, creo que no resulta exagerado utilizar en este contexto el concepto de pre-crimen para expresar esa idea de castigo no tanto por lo que ha pasado cuanto, como destaca ZEDNER, "por lo que no ha pasado y quizás nunca pase" 14 .

La elevada penalidad que tienen asignada gran parte de los tipos preparatorios, pese a su -en muchos de esos casosexiguo contenido de injusto, es un elemento que asimismo merecer ser tenido en cuenta, y que de hecho en mi opinión resulta crucial, a efectos de valorar si nos encontramos ante manifestaciones de un Derecho penal de autor. No es difícil encontrar ejemplos de comportamientos preparatorios en los que tal exceso en la respuesta punitiva resulte patente. Incluso tratándose de supuestos en los que en vía de principio resultaría posible identificar la existencia de un injusto susceptible de legítimo castigo penal -de acuerdo con lo que más adelante se expondrála magnitud de la pena asignada muestra a menudo una clara desproporción entre ésta y la gravedad del hecho. Pero quisiera ahora llamar la atención principalmente sobre los casos, que son abundantes en nuestra legislación, en los que se equipara la pena del comportamiento preparatorio y la del delito-fin consumado. Por limitarme solo ahora a tres ejemplos: se prevé la misma pena para la conducta de poseer programas informáticos destinados estafar que para la estafa consumada (arts. 248.2.b y $249 \mathrm{CP}$ ); se castiga también en idéntica medida el almacenamiento de ejemplares de una obra artística con la intención de distribuirlos que su efectiva distribución o que la explotación económica "de cualquier otro modo" de dicha obra, en todos los casos sin la

14 "Pre-crime and post-criminology?", en Theoretical Criminology, Vol. 11 (2), 2007, p. 2. Por cierto, que el hecho de que un concepto como el de precrime, extraído de la ciencia ficción, y en particular de una ficción distópica (me refiero naturalmente al célebre relato corto de Philip K. Dick, el informe de la minoría, llevado al cine por Spielberg), resulte -siquiera sea en cierta medida- ajustado a nuestra realidad legislativa es por sí solo ya sintomático, y sin perjuicio de lo que más adelante se dirá a este respecto, del modelo del Derecho penal hacia el que avanzamos. 
autorización de los titulares de derechos de la propiedad intelectual (art. 270.1 y 5.a CP); o, en fin, asimismo es igual la sanción que recibe la tenencia de útiles para fabricar moneda falsa que la propia distribución de la moneda falsa o ya alterada (arts. 386.1 y $400 \mathrm{CP}$ ). Ello, ciertamente, no admite justificación posible en atención a razones de injusto y de culpabilidad. Cabe concluir, pues, que en punto a medir la respuesta punitiva del acto preparatorio, y en lo que se refiere, más concretamente, al remanente de penalidad frente a la que resultaría proporcionada a su gravedad, se está teniendo en cuenta en tales supuestos algún parámetro distinto y que, de nuevo entonces, se utiliza el específico hecho cometido como mera coartada para ello.

En mi opinión, en un relevante porcentaje de los delitos de preparación esas "razones" que explican la imposición de una pena más allá del límite representado por la gravedad de la conducta concreta llevada a cabo tienen que ver con la peligrosidad del autor o con su pertenencia a un determinado colectivo de sujetos potencialmente peligrosos. Esto es, la respuesta a por qué el legislador castiga conductas carentes de ofensividad o de ofensividad suficiente $y$, sobre todo, a por qué las castiga con una penalidad mucho mayor a la que resultaría proporcionada a su gravedad pasa aquí tendencialmente por entender que se están castigando en buena medida autores peligrosos y no hechos concretos peligrosos ${ }^{15}$.

15 Lo anterior - procede matizar- no significa que siempre que se trate de un acto preparatorio cuya pena no resulte ajustada a criterios retributivos se haya de seguir necesariamente que estamos ante manifestaciones de un Derecho penal de autor. Es verdad que tal circunstancia, unida a la ligazón que con carácter general es posible trazar-conforme a lo explicado más arriba- entre criminalización de actos preparatorios y Derecho penal de autor -pero que tampoco puede ser tomada, como ya se ha advertido, a modo de presunción-, constituye, según se sugería en el texto, un indicio serio en ese sentido. No se debe perder de vista, con todo, que en ocasiones el exceso de pena (frente a la que resultaría proporcionada a la gravedad del hecho cometido) podría responder prioritariamente a razones de una prevención general exacerbada, en cuyo caso cabría seguir hablando, en los términos en que más adelante se razona -infra: nota 85 - de Derecho penal puramente preventivo pero no ya 


\subsection{Algunos ejemplos. El delito de autoadoctrina- miento terrorista}

Así sucede de manera clara en los delitos de terrorismo, que no en vano se suelen citar como ámbito de plasmación por excelencia del Derecho penal del enemigo. La evolución experimentada en los últimos años por la legislación española en esta materia permite apreciar, efectivamente, cómo a través de distintas técnicas, y entre ellas de manera particular la introducción de figuras preparatorias que llevan consigo penas bastante rigurosas, se impone una decidida orientación a la inocuización de una determinada categoría de sujetos, que pasan a ser considerados como una fuente potencial de riesgos, y ello hasta tal punto que, como expresa CANCIO, "«estar ahí» de algún modo, «formar parte» de alguna manera, «ser uno de ellos», aunque solo sea en espíritu, es suficiente"16.

de un Derecho penal de autor. A este respecto, se ha sostenido que, en términos generales, cuando se trata de actuaciones dirigidas a cometer un delito ulterior la pena pierde sentido como instrumento disuasorio, y en concreto desde el punto de vista de la prevención general negativa, frente a los efectos de tal clase que podría desplegar ya la sanción del delito-fin consumado a la que está encaminada la conducta (AMERICAN LAW INSTITUTE, Model Penal Code and Commentaries (Official Draft and Revised Comments), Part I, 1985, pp. 293 y 294 y 490). Para evitar que una persona mate a otra, apunta también PUSCHKE en esa línea, "se castiga el homicidio, de manera que el sujeto se sienta intimidado. El efecto intimidatorio en relación con la muerte no se ve, sin embargo, incrementado de manera significativa a través de la imposición de una pena a aquél que planifique un homicidio" "“Origen, esencia y límites de los tipos penales que elevan actos preparatorios a la categoría de delito", trad. Fakhouri Gómez, en InDret. Revista para el análisis del Derecho, 4, p. 14). De ser válido dicho razonamiento, que apunta a la inidoneidad del efecto preventivo general negativo en estos casos, podría servir de argumento añadido para justificar que los excesos penológicos, cuando hablamos de la punición de actos preparatorios, responden principalmente al objetivo de neutralizar la peligrosidad del reo (prevención especial) y a partir de ahí para reforzar, aún más, la conexión entre punición (desproporcionada) de actos preparatorios y Derecho penal de autor.

16 “De nuevo: ¿«Derecho penal» del enemigo?", en JAKOBS/CANCIO, Derecho penal del enemigo, $2^{\mathrm{a}}$ ed., Thomson-Civitas, Madrid, 2006, pp. 138 y 139. Vid. asimismo, en referencia específica a la regulación resultante de la reforma de la LO 2/2015, CANCIO MELIÁ, M., "El concepto jurídico- 
Aunque cabría citar otros ejemplos, como el -amplísimo y muy gravemente penado-delito de financiación del terrorismo (art. $576 \mathrm{CP}$ ) o el de traslado al extranjero para colaborar con una organización terrorista, cometer tal clase de delitos o capacitarse para ello (art. 575.3 CP), me gustaría detenerme brevemente ahora en el tipo previsto en el art. 575.2 CP, pues me parece un supuesto especialmente ilustrativo de la tendencia indicada. Tal precepto, como es sabido, castiga -entre otros supuestoscon pena de prisión que puede alcanzar hasta 5 años el autoadoctrinamiento ideológico destinado a capacitarse para cometer alguno de los delitos de terrorismo -en principio, cualquiera de ellos; incluido, por ejemplo, el de enaltecimiento-, y declara expresamente constitutivas de aquella infracción conductas como las de acceder habitualmente a Internet con dicha finalidad o asimismo adquirir o poseer determinados materiales -ni siquiera es necesario haberlos leído (ipreparación de la automotivación para delinquir!)- con el mismo propósito, todo lo cual supone ciertamente aproximar mucho la intervención punitiva al momento del mero pensamiento y las reflexiones ${ }^{17}$.

penal de terrorismo entre la negación y la resignación", en ALONSO/CUERDA/FERNÁNDEZ (dirs.), Terrorismo, sistema penal y derechos fundamentales, Tirant lo Blanch, Valencia, 2018, pp. 121 y 122.

17 Vid., subrayando el estrecho parentesco de este delito con un Derecho penal de autor, entre otros, PUENTE RODRÍGUEZ, L., "La punición del autoadoctrinamiento terrorista: breve pasado y ¿breve futuro?”, en PÉREZ CEPEDA (dir.), Actas del seminario internacional El terrorismo en la actualidad: un nuevo enfoque politico criminal, Ratio legis, Salamanca, 2017, pp. 151 y ss.; CUERDA ARNAU, M. L., "Adoctrinamiento de jóvenes terroristas y sistema penal", en VVAA, Liber Amicorum. Estudios en Homenaje al Prof. Dr. Dr.h.c. Juan $M^{a}$ Terradillos Basoco, Tirant lo Blanch, Valencia, 2018, pp. 1397 y ss.; GALÁN MUÑOZ, A., "Leyes que matan ideas frente a las ideas que matan personas? Problemas de la nueva represión de los mecanismos de captación terrorista tras la reforma del Código penal de la LO 2/2015", en Revista de Derecho penal y Criminología, $3^{\mathrm{a}}$ Época, $\mathrm{n}^{\mathrm{o}} 15$ (enero de 2016), pp. 113 y ss.; BOLDOVA PASAMAR, M. A., "Consecuencias sancionadoras de la radicalización terrorista de los menores de edad y su adecuación al perfil de jóvenes infractores", en ALONSO/CUERDA/ FERNÁNDEZ (dirs.), Terrorismo, sistema penal y derechos fundamentales, Tirant lo Blanch, Valencia, p. 696. 
En realidad, en este caso, el objetivo de castigar la nuda intención delictiva podría decirse que ni siquiera aparece encubierto sino que encuentra reflejo expreso en el texto de la ley, que habla de contenidos (accesibles a través de la red) o de materiales (los que deben ser objeto de adquisición o de posesión) que "estén dirigidos o resulten idóneos para incitar a la incorporación a una organización o grupo terrorista, o a colaborar con cualquiera de ellos o en sus fines" 18 (arts. 575.2. $2^{\circ}$ y $3^{\circ} \mathrm{CP}$ ). Una interpretación fiel al tenor literal, toda vez que se utiliza la conjunción disyuntiva "o" -lo que sugiere que basta con que tales materiales y contenidos cumplan, alternativamente, con uno de esos requisitos o con el otro- permite entender, en efecto, que también cumplimentaría el tipo quien visitara contenidos o poseyera documentos dirigidos a promover tal clase de infracciones aunque no resultaran idóneos para ello. Se vendría a admitir así, haciendo una interpretación estrictamente literal del precepto -posible, por más que desde luego no aconsejable desde un punto de vista garantista-, que basta a efectos típicos con llevar a cabo una conducta carente de cualquier peligrosidad objetiva: tener o consultar materiales inidóneos para incitar a cometer delitos de terrorismo, aunque tales materiales, eso sí, debieran aspirar - estar dirigidos- a poseer dicha aptitud suasoria y también fuera necesario que concurriera en el sujeto la consabida intención de capacitarse para llevar a cabo ese mismo género de actividades (terroristas).

El primer pronunciamiento judicial que recayó sobre este delito (SAN 39/2016, de 30 de noviembre, ponente: Clara Bayarri García) resulta ya muy ilustrativo de los riesgos que implica, en la línea denunciada, su vigencia. Los términos en que se expresa la citada sentencia son, cabría decir, de Derecho penal de autor de libro: "este Tribunal aprecia que los hechos conllevan un plus de gravedad y de antijuridicidad sobre el mero acto de difundir verificado por un estraneus (...), existe una asunción de ideales y fines cercanos al delito de pertenencia, una voluntad

18 El subrayado es añadido. 
dirigida al autoadoctrinamiento buscado de propósito (...). Los 14 documentos hallados en la memoria del teléfono de(l acusado) son complementarios, y definitivamente, acreditativos de la asunción del credo yihadista por (el acusado). De su asunción de los postulados violentos y de la lucha heroica hasta la muerte como medio de obtener la victoria sobre los infieles. El adoctrinamiento está terminado $(\ldots)$ ".19.

En la interpretación, de claro signo expansivo y -en concreto- en clave literal, que en términos mayoritarios han venido realizando nuestros tribunales en los últimos tiempos del delito de enaltecimiento del terrorismo (art. $578 \mathrm{CP}$ ) es posible asimismo advertir la sombra de un Derecho penal de autor. Particularmente, en su aplicación a casos como los de César Strawberry, Valtonyc o La Insurgencia -por citar sólo algunos de los más célebres-, en los que se condena por la publicación de twits, videos o canciones cuya idoneidad objetiva para generar un peligro mínimamente relevante de incremento de la comisión de futuros delitos terroristas -incluso valorado dicho riesgo desde el prisma de la consideración del tipo como delito de clima-

19 Dicho pronunciamiento fue revocado por la STS 354/2017, de 17 de mayo (ponente: Andrés Palomo del Arco), que destaca la "desmesurada extensión" del ámbito de tipicidad de la figura delictiva en examen, a la que califica como "acto protopreparatorio, de mera voluntad 'cuasimanifestada' (es decir, muy incipientemente manifestada)", absolviendo de tal infracción con base en la falta de prueba en el caso concreto del elemento subjetivo del injusto (finalidad de capacitarse para, a su vez, llevar a cabo cualquiera de los delitos de terrorismo) exigido por el tipo delictivo. Poco después, la STS 661/2017, de 10 de octubre (ponente: Alberto Jorge Barreiro) condena por el referido delito a un sujeto que posee en su teléfono móvil vídeos y fotografías incitadores a integrarse en la organización DAESH-Estado Islámico, habiendo quedado acreditado "que en el curso de las comunicaciones telefónicas familiares el acusado manifestó su anuencia a marcharse a Siria a cubrir el puesto dejado por (su hermano) cuando falleciera en el acto suicida a que estaba destinado" y que "el acusado en ninguna de las conversaciones le manifestó a su hermano unas fechas concretas para trasladarse a Siria, pero sí le especificó su asentimiento a realizar la yihad cuando llegara la ocasión oportuna, dejando su decisión para un momento posterior". 
resulta más que cuestionable ${ }^{20}$. Ello evidencia, a mi juicio, que al amparo de la dúctil fórmula del discurso del odio se acaba penando aquí, sobre todo, cómo es el autor o su pertenencia a un determinado colectivo (cuya conexión, por cierto, con el terrorismo o su entorno resulta en tal clase de supuestos muy forzada o directamente inexistente) $)^{21}$.

20 Vid. un análisis crítico de esta línea jurisprudencial en CARBONELL MATEU, J. C., "Crítica a los sentimientos como bien jurídico-penal: el enaltecimiento del terrorismo y la humillación a las víctimas «más allá de la provocación y la injuria»", en ALONSO/CUERDA/FERNÁNDEZ (dirs.), Terrorismo, sistema penal y derechos fundamentales, Tirant lo Blanch, Valencia, 2018, pp. 350352; y MIRA BENAVENT, J., "Algunas consideraciones político-criminales sobre la función de los delitos de enaltecimiento del terrorismo y humillación a las víctimas del terrorismo", en PORTILLA CONTRERAS/PÉREZ CEPEDA (dirs.), Terrorismo y contraterrorismo en el Siglo XXI. Un análisis penal y politico criminal, Ratio Legis, Salamanca, 2016, pp. 110 y 111. Tal autor no duda en considerar que, en los términos en que se halla legalmente configurado, el tipo de enaltecimiento del terrorismo del art. 578 constituye un delito de opinión, que castiga la mera expresión o manifestación de determinados contenidos políticos e ideológicos coincidentes con los de una organización terrorista y que actúa, en consecuencia, como instrumento "de control penal de la discrepancia política e ideológica o del pensamiento simplemente diferente o heterodoxo" ("El delito de enaltecimiento del terrorismo, el de humillación a las víctimas del terrorismo y la competencia de la Audiencia Nacional: ni delito, ni terrorismo, ni competencia de la Audiencia Nacional", en ALONSO/CUERDA/FERNÁNDEZ (dirs.), Terrorismo, sistema penal y derechos fundamentales, Tirant lo Blanch, Valencia, 2018, pp. 302 y ss.). De un tiempo a esta parte se advierte en algunos pronunciamientos jurisprudenciales una interpretación del citado delito más restringida y razonable, que se apoya en la Directiva (UE) 2017/541 del Parlamento Europeo y del Consejo de 15 de marzo de 2017 relativa a la lucha contra el terrorismo, y también en la STC 112/2016, de 20 de junio (ponente: Juan Antonio Xiol Ríos), aunque llegando en realidad más lejos que ésta última -que se conforma con una exégesis del art. 578 como delito de clima- (vid. la STS 354/2017, de 17 de mayo (ponente: Andrés Palomo del Arco), y, sobre todo, la STS 378/2017, de 25 de mayo (ponente: Luciano Varela Castro).

21 Lo expuesto permite confirmar que la consideración del enaltecimiento del terrorismo como tipo autónomo (en vez de en términos de delito preparatorio) y en concreto como delito contra el orden público -en la línea de la tesis interpretativa denunciada en el texto-, supone, como ya me ocupé de justificar en otra trabajo desde una perspectiva más general, un mero artificio que, lejos de salvarla, más bien acentúa la consecuencia de que se acaben castigando hechos que no reúnen la suficiente lesividad material para ser 
En esta misma órbita estimo que cabe situar el tipo de preparación de desórdenes públicos descrito en el art. 557.2 CP. Introducido por la LO 1/2015 de modificación del Código penal, coincidiendo con un momento de elevadísima contestación social en las calles ${ }^{22}$, este precepto supone, en un ámbito delictivo en el que bajo la regulación anterior no se incriminaba ningún acto preparatorio, la criminalización de comportamientos que rebasan la provocación del art. $18 \mathrm{CP}$-no exigen que la incitación a cometer desórdenes públicos sea directa-y que alcanzan incluso al simple reforzamiento de la disposición a delinquir, conducta asimilable estructuralmente a una tentativa de complicidad psíquica ${ }^{23}$. Pese a ello, y bien entendido que no se requiere ningún inicio de ejecución del delito-fin -pues hablamos de actuaciones meramente preparatorias-, su penalidad es la misma que la prevista para el autor del delito de desórdenes públicos consumado ${ }^{24}$; todo lo cual se inscribe en el contexto de una es-

objeto de sanción penal. Vid. ALONSO RIMO, A., “¿Impunidad general...”, cit., pp. 39 y ss.; y asimismo lo apuntado infra (nota 88) a propósito de la posición de JAKOBS en torno al dilema sobre si es preferible concebir esta clase de supuestos que criminalizan el estadio previo a la lesión de un bien jurídico como delitos autónomos o de preparación.

22 El anteproyecto de reforma del Código penal de 2012, que es de donde parte la propuesta de tipificación de este nuevo delito, coincide, de hecho, con el momento álgido de la protesta ciudadana frente a los recortes sociales motivados por la crisis económica iniciada en 2008. Cfr. alguna información estadística a este respecto en ALONSO RIMO, A., "Los nuevos delitos de ¿desórdenes? ¿públicos? Especial referencia a los tipos de incitación o de refuerzo de la disposición a delinquir (arts. 557.2 y 559 CP)", en Estudios Penales y Criminológicos, 35, 2015, p. 389, nota 37.

23 Vid. sobre el particular, subrayando los riesgos que, a la vista de su ambigua configuración legal, concita tal precepto desde el punto de vista del ejercicio legítimo de la libertad de expresión, del derecho de reunión y manifestación y de la crítica política, ALONSO RIMO, A., "Los nuevos...", cit., pp. 365 y ss.

24 Que puede llegar hasta 3 años de prisión; más aún, hasta 6: en la medida en que los hechos se lleven a cabo durante o con ocasión de una manifestación o reunión numerosa -algo que, en el caso de las conductas de que se trata, cabe pensar que será bastante frecuente-; pues ello permitiría apreciar el tipo agravado del art. 557 bis.3, que resulta aplicable al art. 557 en su conjunto, también por tanto a la conducta prevista en su párrafo segundo. El art. 559 CP tipifica acciones parecidas (distribución o difusión pública, a 
trategia más amplia de reformulación de este grupo de delitos marcadamente orientada a la represión de la protesta social y a la persecución del disidente ${ }^{25}$, de aquellos que con acierto define MAQUEDA como las "«nuevas» clases peligrosas" ${ }^{26}$. Otra vez, pues: conductas de escasa o nula lesividad material, castigadas con penas altas, y que todo apunta a que operan en estos ca-

través de cualquier medio, de mensajes o consignas que inciten a la comisión de delitos agravados de desórdenes públicos o que sirvan para reforzar la decisión de llevarlos a cabo), si bien en este supuesto se sancionan más levemente. Sobre la (intrincada) delimitación entre ambos preceptos, puede verse ALONSO RIMO, A., "Los nuevos...", cit., pp. 377 y ss.

25 Ésta es una opinión bastante generalizada. Vid. por todos, CUERDA ARNAU, M. L., "Nos queda la palabra: contra la nueva orientación políticocriminal en materia de orden público", en VVAA. (dirs.), Crímenes y Castigos. Miradas al Derecho penal a través del arte y la cultura, Tirant lo Blanch, Valencia, 2014, pp. 220 y ss.

26 MAQUEDA ABREU, M. L., "La criminalización del espacio público. El imparable ascenso de las "clases peligrosas»", en Revista Electrónica de Ciencia Penal y Criminología, 17-12, 2015, pp. 13 y ss. En sentido similar, PORTILLA habla de "nuevos (viejos) peligros" frente a los que el legislador propone "el control de la peligrosidad, el aislamiento de determinados sujetos a través, esencialmente, de penas y sanciones administrativas" ("La contrarrevolución preventiva emprendida por el Derecho penal y administrativo para hacer frente a los movimientos de protesta y desobediencia civil", en CUERDA ARNAU/GARCÍA AMADO (dirs.), Protección juridica del orden público, la paz pública y la seguridad ciudadana, Tirant lo Blanch, Valencia, 2016, pp. 63 y 64) y VIVES ANTÓN y CUERDA ARNAU sentencian, en referencia a las propuestas de reforma penal en materia de orden público en general -ahora ya convertidas en derecho positivo- que en ellas "la criminalización de la protesta social abandona el principio del hecho para echarse en brazos del más puro Derecho de autor" ("Estado autoritario y adelantamiento de la «línea de defensa penal»", en MAQUEDA/ MARTÍN/VENTURA (coords.), Derecho penal para un estado social y democrático de derecho. Estudios en homenaje al profesor Emilio Octavio de Toledo y Ubieto, Universidad Complutense de Madrid, Madrid, 2016, p. 367). Desde esta perspectiva, que explica la punición de la figura preparatoria del art. 557.2 CP a partir de la finalidad represiva de la protesta social, se revitalizaría la vinculación histórica que subrayara ANTÓN ONECA entre la sanción de actos preparatorios y "delitos políticos y mixtos", entendidos éstos, en el sentido apuntado por MUÑAGORRI, como infracciones "más dirigidas a la autoprotección de instituciones del Estado que a la protección de su condición democrática" y que, sobre esa base, conduce a un Derecho penal "que actúa en la esfera de la voluntad y la sospecha" (MUÑAGORRI LAGUÍA, I., "Punición...”, cit., pp. 1006 y 1007; cfr. también p. 1004). 
sos como ocasión para criminalizar una determinada categoría de sujetos, en términos que desprenden un inevitable aroma de "vieja" peligrosidad social.

\section{Actos preparatorios y Derecho penal de la peligrosidad. Dos casos paradigmáticos}

\subsection{La regulación del Model Penal Code estadouni- dense}

En otros ámbitos y por parte de algunos autores la fundamentación de la pena de los actos previos a la consumación en la mera peligrosidad del autor, más que en la gravedad del hecho concreto ya cometido, es algo que se acepta de forma mucho más abierta. Los redactores del Código penal modelo estadounidense, por ejemplo, singularizan entre los principales cometidos que cabe atribuir al Derecho penal respecto a la incriminación de los llamados inchoate offences (tentativa, conspiración y proposición) -y que se prevé en relación con la generalidad de los delitos- el de combatir el "especial peligro" de los sujetos que, al realizar una conducta dirigida a la consumación de una infracción ulterior, reflejan una disposición hacia dicha actividad que va más allá de ese caso concreto ("not alone on this occasion but on others" $)^{27}$. De acuerdo con ello, no sorprende que declaren tales figuras "de magnitud comparable" a los delitos consumados que constituyen su objeto ${ }^{28}$ y que equiparen generalmente las penas de todas ellas con las de los correspondientes delitos-fin consumados ${ }^{29}$. El Model Penal

27 AMERICAN LAW INSTITUTE, Model Penal... ”, cit., p. 294.

28 Ibidem, p. 295.

29 Se excepciona solo de esta regla general los casos de inchoate offences dirigidos a la realización de delitos de extrema gravedad (parágrafo $5.05 \mathrm{Model}$ Penal Code). La justificación que se ofrece es que en delitos tan relevantes la sanción obedece a razones de disuasión general (prevención general negativa) y que a tal finalidad es dudoso, en la concepción de los autores del Model Penal Code, que la pena del inchoate offence pueda añadir alguna 
Code $^{30}$, se dice -en términos coherentes con lo explicado-, considera al preparador (que lleva a cabo en concreto una proposición) y al autor del delito consumado "igual de peligrosos" y de ahí que homologue con carácter general la penalidad de ambos supuestos $^{31}$. Sus propios redactores justifican, de hecho, expresamente el citado criterio penológico aduciendo que desde el punto de vista de la "disposición antisocial del autor" y de la "necesidad demostrada de una sanción correctiva" -parámetros que, a su juicio, deben informar la distribución de la pena-normalmente habrá poca diferencia entre la gravedad de la respuesta necesitada en función de si el delito llega a consumarse o fracasa el plan ${ }^{32}$. Y no solo eso. En este mismo contexto de la discusión sobre la fundamentación de la penalidad de la tentativa se ha llegado a argumentar que el castigo deba ser ya no igual sino incluso mayor en el caso de la tentativa que en la consumación, por cuanto aquí el sujeto no ha conseguido todavía su objetivo delictivo y desde ese prisma puede resultar especialmente peligroso si no está confinado ${ }^{33}$.

eficacia, más allá de la amenaza que ya entraña la pena del delito consumado, la cual además, por definición, el autor ignora. Vistas las cosas desde esta perspectiva, una pena menor para el inchoate offence puede bastar para responder a cualquiera que sea el "peligro representado por el autor" (AMERICAN LAW INSTITUTE, Model Penal..., cit., p. 490).

30 En adelante: $M P C$.

31 LOEWY, A. H., Criminal Law in a nutshell, $5^{\mathrm{a}}$ ed., West, Saint Paul, 2009, p. 238. Cfr. también, críticamente, señalando que tal equiparación de penas constituye la decisión más doctrinaria y menos afortunada de los redactores del MPC, ROBINSON, P.H. y DUBBER, M.D., "The American Model Penal Code: A Brief Overview", en New Criminal Law Review, Vol. 10, Number 3, 2007, pp. 329 y 336.

32 Ibidem, p. 490.

33 Cfr. LOEWY, A. H., Criminal Law..., cit., p. 226, aludiendo en este caso a la opinión de otros autores. Los redactores del $M P C$ rechazan la posibilidad de castigar más gravemente el inchoate offence que el substantive offence, alegando a tal efecto que "es el peligro de que la conducta del autor pueda culminar en su consumación" lo que justifica la tipificación del delito inchoate (AMERICAN LAW INSTITUTE, Model Penal ..., cit., p. 490). Pero esta última afirmación no resulta coherente con la línea de pensamiento que mantienen con carácter general para justificar la punición de esta clase de 
Se aprueba, pues, de manera clara que en tales supuestos se trate, sobre todo, de reaccionar frente al autor y su peligrosidad, y no tanto frente a su conducta concreta ${ }^{34}$.

\subsection{Los quasi reati del ordenamiento penal italiano}

En el caso de la regulación italiana tal clase de planteamiento se aprecia en términos mucho más evidentes. El accordo para cometer un delito y la istigazione -figuras homólogas a nuestra conspiración y proposición y que se tipifican en el Código penal italiano ${ }^{35}$ respecto de la generalidad de los delitos- tienen asignada como consecuencia jurídica en dicho sistema una medida de seguridad (art. $115 \mathrm{CPI}$ ) cuyo presupuesto esencial se cifra en lo que ya de entrada se denomina legalmente "peligrosidad social" (arts. 202 y 203 CPI). La aplicación de las medidas ("administrativas") de seguridad está prevista con carácter general en el ordenamiento penal italiano para las personas socialmente peligrosas que hayan cometido algún hecho definido por la ley como delito pero también para otros casos, en los que así se determine expresamente, de personas socialmente peligrosas que hayan llevado a cabo "un hecho no previsto por la ley como delito" (art. 202 CPI). Y en esta última categoría de supuestos, que se denominan por la doctrina quasi reati ${ }^{36}$, se

figuras delictivas y que se apoya, en el sentido explicado, en el especial peligro que representa el autor, en su disposición a cometer el delito, en referencia por tanto a esa ocasión pero también a otras.

34 Vid. HUSAK, quien -en el marco de un planteamiento más general que, como es conocido, admite las privaciones de libertad con base en razones estrictamente preventivas (preventive detention) como castigo penal legítimo- cita los supuestos de attempt, conspiration y solicitation como ejemplos paradigmáticos de figuras de dicha naturaleza -que se justifican por el daño futuro (future harm) y no por el ya causado- generalmente aceptadas ("Lifting the Cloak: Preventive Detention as Punishment", en 48 San Diego Law Review, 2011, pp. 1187 y ss.).

35 En adelante: CPI

36 Vid. VASALLI (voz "Quasi-reato", en Enciclopedia del Diritto, XXXVIII, Giuffrè, Milano, 1987, p. 35) destacando que tal acepción está formalmente autorizada por el propio Código, en concreto por los arts. 202.2 y 229.2, que contemplan de forma expresa que se pueda aplicar una medida de seguridad a un "fatto non preveduto dalla legge come reato". 
incluyen, además del delito imposible (art. 49.2 CPI), las citadas figuras de accordo per commettere un delitto y de istigazione. La peligrosidad que autoriza la imposición de la medida es posible apreciarla tanto respecto de personas imputables como inimputables y, pese a su reconocida legalmente naturaleza "social", se vincula a la probabilidad de comisión de delitos futuros ${ }^{37}$. Esta circunstancia se ha de inferir de una serie de criterios legales entre los que se cuentan los motivos para delinquir y el carácter del reo, sus antecedentes penales y judiciales, y "en general" su conducta y su vida anterior al delito, o sus condiciones de vida individual, familiar y social (art. $133 \mathrm{CPI}$ ).

La medida prevista en concreto para la conspiración y proposición italianas es la libertad vigilada (arts. 215.2 y 229 $\mathrm{CPI}$ ), a la que la ley asigna una duración mínima de 1 año (art. 228.5 CPI) y ningún límite máximo; es decir, que estamos hablando de una medida de seguridad indefinida, cuya aplicación en estos casos se produce, además, con relativa frecuencia (frente a lo que ocurre con las medidas de seguridad en general en el sistema italiano $)^{38}$. Pero lo que ahora más interesa subrayar es que, de acuerdo con su regulación, en las indicadas figuras preparatorias la peligrosidad objetiva del hecho pierde toda relevancia a efectos de determinar la aplicación de la consecuencia jurídica (la medida de seguridad). La conducta en sí misma (conspirar o proponer), a la que la propia ley -no se olvide- califica como no delictiva, se convierte así en mera ocasión para valorar los síntomas del estatus de persona socialmente peligro-

37 Art. 203 CPI: 1. "Agli effetti della legge penale, è socialmente pericolosa la persona, anche se non imputabile o non punibile, la quale ha commesso taluno dei fatti indicati nell'articolo precedente quando è probabile che commetta nuovi fatti preveduti dalla legge come reati". 2. "La qualità di persona socialmente pericolosa si desume dalle circostanze indicate nell'articolo 133".

38 Vid., destacando ambos aspectos, MARTUFI, A., "Nulla periculositas sine actione? Pericolosità sociale e materialità del fatto alla prova delle fattispecie di quasi reato", en Rivista Italiana di Diritto e Procedura Penale, Vol. $58, \mathrm{n}^{\circ} 2,2015$, p. 823 (nota 12 ) y p. 819 respectivamente. 
sa y, con ello, tal peligrosidad se erige en el fundamento decisivo de la sanción ${ }^{39}$. La idea básica subyacente es, pues, en los términos en que la sintetiza VASALLI, la siguiente: de un hecho penalmente no relevante puede emerger una verdadera y propia peligrosidad criminal ${ }^{40}$. Así las cosas, resulta de todo punto coherente la asociación que se establece -al englobarse las tres bajo el título común de quasi reati- del acuerdo para delinquir y la instigación con la figura del delito imposible, ésta última citada tradicionalmente como ejemplo de vulneración manifiesta del principio del hecho ${ }^{41}$. Cabe constatar, en suma, que la regulación de los actos preparatorios "de la Parte General” del Código penal italiano conserva una profunda huella de la Escuela positiva (lo mismo que el sistema de medidas de seguridad italiano en su conjunto $)^{42}$.

39 Vid. NOTARO, D., "Art. 202", en PADOVAnI, Codice Penale, T. I, VI ed., Giuffrè, Milano, 2014, p. 1255; y MARTUFI, A., "Nulla periculositas..., cit., pp. 818 y ss., críticamente, postulando este autor la necesidad de impulsar una revalorización garantista del hecho en el marco del juicio de la peligrosidad social y de la aplicación de las medidas de seguridad, particularmente en el caso de los quasi reati, y formulando propuestas encaminadas a corregir por vía interpretativa el planteamiento -reflejado en el texto- al que aboca la regulación legal.

40 Según explica el autor, "el Derecho italiano no acepta la punición de un hecho que no haya alcanzado un cierto umbral de peligro o cuando la ideación no vaya seguida de un principio de ejecución idónea", pero a la vez "no desconoce la peligrosidad que el sujeto a través de aquella ideación o aquel acuerdo (...) puede haber revelado; y no quiere renunciar a seguirlo en sus movimientos ulteriores, aun cuando haya debido declarar la no punibilidad (de tales hechos). Lo que se ha revelado estéril una vez no está dicho que no pueda llegar a madurar en una ocasión sucesiva" (voz "Quasi-reato", cit., p. 36). Ahora bien, como el propio VASALLI resalta en otro momento de su exposición: si bien no parece que dichas conductas sean "verdaderos y propios delitos", la medida de seguridad sí es en cambio "una verdadera sanción penal" (ibidem, p. 36).

41 COBO DEL ROSAL, M./VIVES ANTÓN, T. S., Derecho penal. Parte General, $5^{\text {a }}$ ed., Tirant lo Blanch, Valencia, 1999, pp. 349 y 350.

42 También en la Parte Especial se prevén tipos de preparación, principalmente en materia de terrorismo. Algunos de ellos, por la clase de conductas que incriminan, la laxitud con que se formulan sus descripciones típicas y la entidad de las penas que tienen establecidas (cfr. FRONZA, E., "Tutela penal 


\section{3. ¿Medidas de seguridad predelictuales? Levantar el velo}

Creo que también en el caso de nuestro derecho positivo, contempladas las cosas desde una perspectiva material, más allá de etiquetas, cabría decir que las penas de un importante número de delitos preparatorios operan en buena parte con arreglo a un planteamiento muy similar al expuesto en líneas anteriores; esto es, como una suerte de medidas de seguridad predelictuales o, si se quiere, como un pre-castigo que se impondría a un would-be criminal -utilizando la terminología de Philip K. Dick-43 ${ }^{43}$. Ciertamente, el hecho de que en muchos de estos casos la pena del

anticipada y normativa antiterrorismo en el ordenamiento italiano", en AMBOS/MALARINO/STEINER (eds.), Terrorismo y Derecho penal, KonradAdenauer-Stiftung, Berlín, 2015, pp. 250 y ss.), permitirían pensar a priori en problemas similares a los que plantean una parte relevante de nuestros delitos de preparación, que en los términos más arriba explicados permiten ser contemplados como manifestaciones de un Derecho penal de autor. Con todo, según apunta la citada autora, los jueces italianos están llevando a cabo en dicho ámbito delictivo una interpretación de corte garantista que favorece una aplicación contenida de tales figuras (ibidem, pp. 255 y ss.). Esto es algo que, como se ha comprobado supra (epígrafe 1.1.), no es posible afirmar que suceda en nuestro caso. Por otra parte, resultan asimismo de especial interés en este contexto las denominadas misure di prevenzione personali contenidas en el Decreto legislativo de 6 de septiembre de 2011, n. 159 (Codice delle leggi antimafia e delle misure di prevenzione, nonché nuove disposizioni in materia di documentazione antimafia, a norma degli artcioli 1 e 2 della legge 13 agosto 2010, n. 136), reformado por la Ley de 17 de octubre de 2017, n. 161. En particular las aplicables por la autoridad judicial, como la de "sorveglianza speciale di pubblica sicurezza", que se prevén para aquellos sujetos que, reuniendo el presupuesto común de resultar "peligrosos para la seguridad pública", lleven a cabo, actuando en grupo o de manera aislada, actos preparatorios objetivamente relevantes dirigidos a subvertir el sistema estatal con la comisión de determinados delitos como el de estragos, incendios, insurrección armada contra los poderes del Estado, constitución de banda armada o secuestro, entre otros; o asimismo para los que realicen actos preparatorios objetivamente relevantes destinados a reconstruir el partido fascista a través, en especial, de la exaltación o de la práctica de la violencia (art. $4.1 \mathrm{~d}$ y f y art. 6 del citado Código antimafia).

43 PAWLIK habla de "custodia de seguridad anticipada" (vorweggenommenen Sicherungsverwahrung) en referencia a la función que desempeñan de facto en el Derecho penal alemán el delito de pertenencia a asociación terrorista $(\S 129 \mathrm{a} S t G B)$ y el de preparación de un delito violento grave contra la 
hecho preparatorio sea la misma que la del hecho futuro (delitofin) sugiere de forma inevitable esa idea de castigo adelantado (por lo que no ha pasado todavía, como antes se apuntaba). O, dicho de otra forma: indica que se está reaccionando ante un hecho futuro y tratando de neutralizar con ello la peligrosidad del autor, por mucho que se utilice como coartada la realización de un hecho externo, que, según se razonaba en páginas anteriores, o bien no es nada ofensivo o que, si lo es, contiene de cualquier modo mucha menos ofensividad de la que podría justificar la pena que tiene asignada ${ }^{44}$.

seguridad del Estado ( $\$ 89$ StGB) (Der Terrorist und sein Recht. Zur rechtstheoretischen Einordnung des modernen Terrorismus, C. H. Beck, Múnich, 2008, p. 43). Por su parte, HUSAK ("Lifting...", cit., pp. 8 y ss.), en el sentido antes indicado, y también ROBINSON (Principios distributivos del Derecho penal. A quién se debe sancionar y en qué medida, trads. M. Cancio e I. Ortiz de Urbina, Marcial Pons, 2012, pp. 135 y ss.), aunque manteniendo cada uno distinto criterio respecto de su legitimidad, denuncian la existencia de un amplio número de previsiones legales en el derecho estadounidense -entre las que incluyen los tradicionales inchoate offences de tentativa, conspiración y proposición y otras figuras delictivas preparatorias- que encubren, bajo la apariencia de pena retributiva, internamientos preventivos ("preventive detention"). La denominación pre-castigo, como observa ZEDNER ("Pre-crime and pre-punishment: a health warning", en Criminal Justice Matters, 81: 1, 2010, p. 25), y que dicha autora usa en referencia a una gama de supuestos que exceden asimismo los tipos preparatorios, tiene la ventaja de resaltar el aspecto punitivo de la reacción-que, por lo demás, en los casos a los que aquí se alude (delitos de preparación del Código penal español) resulta incuestionable, pues el legislador las llama directamente "penas" y son en su gran mayoría privativas de libertad-. Por otra parte, la utilización del prefijo "pre" (al hablarse de pre-castigo o de pre-punishment) quizás permita salvar la contradicción lógica que, como subraya ROBINSON (Principios..., cit., pp. 138 y 139), entraña "punir" -acción que mira al pasado, al delito previo cometido- la peligrosidad (del autor) -que mira al daño futuro, al delito por cometer-.

44 A partir de lo dicho, y siempre desde la óptica material indicada, estimo que cabe relativizar la afirmación de que la regulación italiana, en lo que se refiere a la previsión de medidas de seguridad para sujetos peligrosos por "hechos no delictivos", sea algo "que no encuentra equivalente en el panorama legislativo europeo" (MARTUFI, A. "Nulla periculositas..., cit., p. 822) o la de que soluciones de esta clase se encuentren "fuera de nuestro marco de discusión” (SILVA SÁNCHEZ, J. M., El nuevo Código penal: cinco cues- 
Se debe levantar el velo, lift de cloak -en expresión de HUSAK $^{45}$-. Ahora bien, denunciar esta realidad, esta disolución del principio del hecho, pienso que no puede hacerse para a continuación asumirla ${ }^{46}$; ni siquiera dentro de determinados márgenes -en teoría, restringidos-, los que constituirían un Derecho penal del enemigo o de tercera velocidad o una variante del Derecho de guerra ${ }^{47}$. Tampoco para acabar reconduciendo la legitimidad del internamiento preventivo a otros sectores del ordenamiento jurídico (distintos al penal) ${ }^{48}$.

En coherencia con lo anterior, y por lo que respecta en concreto a la cuestión que es objeto de estudio en este trabajo (la criminalización de los actos preparatorios), procede, pues,

tiones fundamentales, Bosch, Barcelona, 1997, p. 132, en referencia al caso de la tentativa irreal del Código penal italiano, que, en el sentido más arriba explicado, constituye, junto con el acuerdo para delinquir y la instigación, la tríada de los quasi reati y para los que se contempla la imposición de una medida de seguridad fundamentada en la peligrosidad del autor).

45 Expresión que remite claramente al título del célebre trabajo de ROBINSON "Punishing Dangerousness: Cloaking Preventive Detention as Criminal Justice", 114 Harvard Law Review, 2001. Cfr. HUSAK, D., "Lifting...", cit., p. 1180.

46 Vid. HUSAK, para quien la privación de libertad preventiva puede ser defendida como pena legítima en el marco del sistema penal general, sin perjuicio de que deba ser sometida a algunas limitaciones ("Lifting...", cit., pp. 1173 y ss., pp. 1203 y ss.).

47 Vid. respectivamente, JAKOBS “ ¿Terroristas como personas en Derecho?”, trad. M. Cancio Meliá, en JAKOBS/CANCIO, Derecho penal del enemigo, Thomson-Civitas, Madrid, 2006, pp. 74 y ss.), SILVA SÁNCHEZ (La expansión del Derecho penal. Aspectos de la Política Criminal en las sociedades postindustrinales, $3^{\mathrm{a}}$ ed., Edisofer-B de F, Montevideo, Buenos Aires. 2011, pp. 184 y ss.) y PAWLIK (Der Terrorist..., cit., pp. 25 y ss.), quienes consideran legítimo, en un marco de excepcionalidad y en referencia a determinados fenómenos delictivos, un adelantamiento extremo de la intervención punitiva orientado a neutralizar la peligrosidad del autor y acompañado de penas graves ("de cárcel”), soslayando, por consiguiente, y entre otras, las limitaciones derivadas del principio de culpabilidad. Se trata, en definitiva, como se suele reconocer explícitamente, del abandono de la perspectiva del hecho pasado por la del hecho futuro.

48 Tal es la tesis que defiende, entre otros, ROBINSON (Principios..., cit., pp. 156 y ss.). 
quitar el disfraz y reclamar la derogación -0 , en su defecto, la reformulación- de todos aquellos tipos de preparación que, de acuerdo con lo explicado en páginas anteriores, cabe concluir que son expresión de un Derecho penal de autor. Lo que aceptamos en general "camuflado" o bajo la apariencia formal de pena de un delito (preparatorio), seguramente nos sería más difícil de aceptar si lo llamáramos medida de seguridad predelictual o pre-castigo. De esta forma resultaría más evidente que se trata de supuestos en los que "la condena precede al juicio"49, o en los que, sencillamente, se persigue la inocuización preventiva -más allá de los límites que marca la gravedad del hecho cometido- de una persona responsable, lo cual, en el sentido destacado por PEÑARANDA RAMOS, "puede interpretarse, como FEUERBACH, como el castigo anticipado de un hecho futuro, fáctica y normativamente incierto, para el que el Estado carece de legitimación" ${ }^{50}$.

\section{La deriva hacia el Estado preventivo}

Se sigue de lo hasta aquí expuesto que las consecuencias jurídicas asociadas a un numeroso grupo de tipos preparatorios obedecen, con independencia de su etiqueta formal, a la lógica de las medidas de seguridad pre-delictuales o de lo que podrían

49 En este sentido resulta ilustrativo el hecho, señalado por ROBINSON, de que tradicionalmente en el ámbito doctrinal estadounidense haya generado más reticencias el internamiento preventivo visto como medida cautelar -impuesta antes del juicio- que disfrazado de pena. Sin embargo, como afirma el citado autor: "la crítica principal a la utilización del internamiento preventivo como medida cautelar, que la condena precede al juicio, también puede aplicarse a las reformas que autorizan el internamiento preventivo posterior a la condena. El internamiento por tiempo superior al tiempo merecido se justifica por su capacidad para prevenir delitos cuya futura comisión se predice. Tal internamiento no sólo sanciona por un delito por el cual el sujeto todavía no ha sido condenado, sino que de hecho le sanciona por un delito que todavía no ha cometido" (la cursiva es añadida) (Principios..., cit., p. 140).

50 En LASCURAÍN SÁNCHEZ (coord.), Introducción al Derecho penal, $2^{\mathrm{a}}$ ed., Thomson-Civitas, Pamplona, 2015, pp. 286 y 287. 
denominarse pre-castigos, y ello, en síntesis, en tanto que se fundamentan en la peligrosidad del autor (y no en el hecho cometido). Se debe tener en cuenta, además, que estamos hablando aquí de una peligrosidad cuya valoración no es ya que se deje en manos del juez y de sus -necesariamente, hoy por hoy-inciertos pronósticos de peligrosidad ${ }^{51}$ sino que directamente se presume (iuris et de iure) por el legislador -de modo que cabría hablar de una especie de "pronóstico de peligrosidad legislativo"- y no es susceptible de ninguna revisión ulterior. Ello favorece naturalmente la aplicación de la respuesta punitiva prevista $^{52}$, pero a la vez muestra que se está reaccionando, más que ante la peligrosidad "real" de un individuo concreto, y sobre todo, contra una determinada categoría de autor (presuntamente peligroso) ${ }^{53}$. Se ha podido reprochar a las medidas de seguridad cuya imposición se prevé a partir de una valoración individualizada de la peligrosidad del sujeto su carácter arbitrario sobre la base de la incapacidad de los métodos de predicción para determinar tal peligrosidad con un suficiente grado de certeza, y asimismo por tal motivo se ha cuestionado, con razón, su virtualidad como

51 Vid. MARTÍNEZ GARAY, L., "La incertidumbre de los pronósticos de peligrosidad. Consecuencias para la dogmática de las medidas de seguridad", en InDret. Revista para el análisis del Derecho, 2, 2014; LA MISMA: "Errores conceptuales en la estimación de riesgo de reincidencia. La importancia de diferenciar sensibilidad y valor predictivo, y estimaciones de riesgo absolutas y relativas", Revista Española de Investigación Criminológica, $\mathrm{n}^{\mathrm{o}} 14$ (2016); MARTÍNEZ GARAY, L./MONTES SUAY, F., "El uso de valoraciones del riesgo de violencia en Derecho Penal: algunas cautelas necesarias", InDret. Revista para el análisis del Derecho, n 2/2018.

52 El Código penal italiano contemplaba - expresamente- hipótesis de peligrosidad presunta hasta el año 1986, en que fueron derogadas. Su desaparición de la regulación legal, según constata la doctrina de dicho país, ha supuesto en la práctica un gradual abandono del uso de las medidas de seguridad privativas de libertad. Sobre ello, MARTUFI, A., "Nulla periculositas ..., cit., p. 819, con ulteriores referencias.

53 En una línea que resulta coherente con el "nuevo paradigma actuarial", desde el que "el control ya no busca proyectarse sobre individuos concretos sino que se expande por el tejido social incidiendo sobre una población segmentada en categorías de sujetos que se perciben como un riesgo" (MAQUEDA ABREU, M. L., "La criminalización...”, cit., p. 6). 
instrumento para combatir de manera eficaz el delito ${ }^{54}$. Cuando, como es el caso, se renuncia a pronosticar la peligrosidad del autor de manera individualizada y la misma directamente se presume tales críticas devienen todavía más fundadas. Se trata, por tanto, aquí de medidas no solo predelictuales sino también arbitrarias e ineficientes. Por si lo anterior no bastara, tampoco se debe perder de vista su notable -en algunos casos extraordinario- contenido aflictivo: hablamos de sanciones privativas de libertad de hasta 5 años en el caso del autoadoctrinamiento terrorista (art. 575.2 CP), de hasta 12 años por tenencia de útiles para alterar moneda (art. 400 en relación con el art. 386.1 CP), de hasta 15 años por financiar delitos de terrorismo (art. 576.2 $\mathrm{CP}$ ); de la misma pena, en fin, que la prevista para el autor del delito-fin consumado en muchos otros supuestos (hasta 4 años de prisión, por ejemplo, por elaborar o poseer escritos idóneos para fomentar el odio con la finalidad de distribuirlos [art. 510.b $\left.\mathrm{CP}^{55}\right]$ ). Nada que ver, pues, con la libertad vigilada que sugiriera RODRÍGUEZ MOURULLO para la conspiración, proposición y provocación, como alternativa al régimen de criminalización genérica de tales supuestos con la pena inferior en uno o dos grados a la del delito consumado que se establecía en nuestro Código penal anterior ${ }^{56}$.

54 Vid. MARTÍNEZ GARAY, L., "La incertidumbre...,", cit., pp. 53 y ss.

55 En este caso la infracción principal es la de provocación a la discriminación prevista en el art. 510.1a) CP, respecto de la cual la propia conducta de efectiva distribución cabe considerar ya en realidad una modalidad ejecutiva. Sobre ello, ALONSO RIMO, A., “¿Impunidad general...”, cit., p. 54.

56 El citado autor, en rigor, habla de medida de seguridad en general frente a pena, como solución más adecuada (optando de cualquier modo, por un sistema cerrado o de numerus clausus de punición), si bien toma como modelo el ejemplo de la legislación italiana, en la que, como ya vimos, se prevé en concreto la libertad vigilada para los casos de referencia, y alude asimismo en esa línea a la regulación del CP de 1822, en la que se contemplaba "la vigilancia especial de las autoridades en los casos que determine la Ley" para hipótesis similares (RODRÍGUEZ MOURULLO, G., "La punición...", cit., pp. 303 y 304). 
En suma, tal y como yo lo veo: asistimos al castigo de estados peligrosos predelictuales y presuntos con penas -en general- muy severas y que comportan, consiguientemente, una importante e ilegítima vulneración de las libertades.

Me gustaría añadir en este punto un ejemplo más, que a mi juicio pone de relieve de manera expresiva esta deriva preventiva: de acuerdo con el tenor literal del art. 579.1 es posible castigar al que difunde públicamente consignas que tuvieran como finalidad incitar a otros a la comisión de delitos de terrorismo incluso si aquéllas no son objetivamente idóneas a estos efectos (luego: puro Derecho penal de la voluntad ${ }^{57}$ ) con una pena que podría alcanzar los 30 años de prisión $(!)^{58}$.

57 Del mismo modo que se hacía constar más arriba, con ocasión del análisis los tipos del art. 575.2. $2^{\circ}$ y $3^{\circ} \mathrm{CP}$-de redacción, en lo que aquí interesa, muy similar, y que se advierte también en el art. 577.2 CP (utilización de la conjunción disyuntiva "o")-, no se defiende aquí, ni mucho menos, que tal sea la interpretación más adecuada del precepto; simplemente se pone de manifiesto que resulta posible en atención a su tenor literal y que es incluso, se diría, la que se ajusta más fielmente al mismo.

58 Siempre que el mensaje o consigna en cuestión estuviera dirigido a incitar a la comisión de alguno de los delitos de terrorismo del art. 573.1 CP que implicara la muerte de una persona, pues en tal caso, efectivamente, la pena inferior en uno o dos grados a la establecida para el delito-fin ("la de prisión por el tiempo máximo previsto en este Código": prisión permanente revisable [art. 573 bis $1.1^{\circ} \mathrm{CP}$ ]) tendría su techo máximo en 30 años de prisión (art. $70.4 \mathrm{CP}$ ). Vid. denunciando la desorbitada penalidad prevista en el art. 579.1 CP -que, como observa la autora, habla por sí misma ("no parece requerir mayores comentarios")-, y destacando cómo unos hechos concretos (colocar varios posts en un foro yihadista con una firma digital visual confeccionada por el propio sujeto y "consistente en un ordenador, con una pistola simulada que había adquirido para ello, y de un Corán, además de un gesto con la mano amenazante") que juzgados conforme a la regulación previa a la LO 2/2015 merecieron una pena de 2 años de prisión y 10 años de inhabilitación absoluta sería posible castigarlos ahora, tras la reforma operada por la citada Ley, con una privación de libertad que podría llegar al -drástico- límite máximo ya señalado, BARBER BURUSCO, S., "Del delito de "difusión" o "propaganda" terrorista a la desmesurada expansión de la punición de actos preparatorios", Cuadernos de Política Criminal, 116-2, 2015 , pp. 61 у 62. 
En este estado de cosas, creo que no es exagerado sostener que nuestro legislador se ha adentrado en una senda muy resbaladiza y que conduce, como han subrayado VIVES ANTÓN y CUERDA ARNAU, al "Estado autoritario" o "preventivo" y, a partir de ahí, al "Estado arbitrario"59.

A fin de refrendar la afirmación anterior, en lo que se refiere de nuevo concretamente a la cuestión de la punición de los actos preparatorios y sin perjuicio de todo lo hasta ahora expuesto, cabe destacar que las sanciones de los tipos de preparación de la Parte Especial son en general mucho más graves ahora de lo que lo eran las previstas para los delitos preparatorios del Código penal franquista, que por norma $-\mathrm{y}$ aunque había alguna excepción- resultaban muy inferiores a la del delito principal consumado. Cito solo un ejemplo (ilustrativo): el antiguo delito (de desórdenes públicos) del art. 248 del CP de 1944/1973 castigaba a los que "dieren gritos provocativos de rebelión o sedición en cualquier reunión o asociación o en lugar público u ostentaren en los mismos sitios lemas o banderas que provocaren directamente a la alteración del orden público" con arresto mayor (de un mes y un día a 6 meses), mientras que en el Código penal vigente conductas definidas de forma mucho más flexible y que implican menor contenido incitador -reforzar la

59 Los autores citados utilizan tales expresiones en referencia al fenómeno de adelantamiento de la línea de defensa penal que está presente en general en la legislación penal contemporánea -aunque aludiendo particularmente a los delitos de posesión y a los de pertenencia-. El principio del hecho y el de ofensividad "tienen la virtud de ser excelentes indicadores de las oscilaciones desde una política criminal democrática hacia una política criminal autoritaria", tal y como recuerdan VIVES y CUERDA, quienes asimismo destacan que el Estado autoritario implica la extensión, también al Derecho penal, de lo que DENNINGER denominara el "Estado preventivo" y que se traduce en "el desplazamiento de la seguridad jurídica por la seguridad de los bienes jurídicos". El legislador actual transita señaladamente en esa dirección, hasta el punto de que su acusada preocupación por criminalizar el futuro, "lo que todavía no tiene realidad alguna", permite hablar de una evolución del Estado autoritario hacia el Estado arbitrario ("Estado autoritario...", cit., pp. $368-370$ y nota 20 , y pp. 380 y 381 ). 
disposición (a cometer desórdenes públicos)- comportan prisión de hasta 3 años, que, según veíamos, fácilmente pueden llegar hasta 6 -las mismas penas que las del delito-fin consumado, en sus modalidades básica y agravada respectivamente-

En la misma línea, considero significativo recordar cómo hemos pasado de que tradicionalmente apenas recayeran sentencias de apologías -ni en el ámbito del terrorismo ni en general ${ }^{60}$ a que el enaltecimiento del art. $578 \mathrm{CP}$ sea en estos momentos una de las infracciones de terrorismo que más causas y condenas motiva $^{61}$, debiendo tenerse en cuenta, además, los términos -de signo claramente expansivo, que llevan el tipo más allá del terreno de la preparación, interpretándolo como delito formal y, por esa vía, en clave de Derecho penal de autor- en los que, según se ha destacado antes, se viene aplicando de manera mayoritaria; y asimismo, en fin, el resurgimiento que, con arreglo también a lo explicado más arriba, acusa la criminalización de actos preparatorios en relación con las infracciones políticas (en sentido amplio).

\subsection{La experiencia anglosajona}

De otro lado, por lo que decía antes del carácter resbaladizo de la senda emprendida, tampoco se puede desconocer que en ordenamientos jurídicos no tan ajenos a nuestro entorno cultural, como por ejemplo el británico, más allá de que se castigan los clásicos inchoate offences (attempt, conspiracy y encouraging/ assisting crime) de acuerdo con un sistema de numerus apertus ${ }^{62}$

60 Ni bajo el régimen político anterior a la Constitución de $1978 \mathrm{ni}$, en realidad, tampoco a lo largo del período codificador español (vid. BELLOCH JULBE, J. A., "Contemplación jurisprudencial sobre el binomio libertad de información terrorismo: la apología del terrorismo", en Estudios jurídicos en honor de J. Gabaldón López, Madrid, 1990, pp. 17, 27 y ss. y 36).

61 Cfr. MIRA BENAVENT, J., "Algunas consideraciones...", p. 110, que habla a este respecto de "auge inusitado" del citado delito.

62 Vid. ASHWORTH, A., "Attempts», en DEIGH/DOLINKO (eds.), The Oxford Handbook of Philosophy of Criminal Law, Oxford Handbooks Online, 2011, pp. 126, 127, nota 7, p. 141. 
y de que el recurso en general a la tipificación penal de conductas preparatorias (preparatory or pre-inchoate offences ${ }^{63}$ ) se halla en clara expansión ${ }^{64}$, la equiparación entre la penalidad de actos preparatorios y delitos-fin consumados resulta bastante generalizada. Ello hasta el punto de que se pueda sancionar con imprisonment for life la conspiración (para delitos que lleven asignadas dicha pena $)^{65}$, lo mismo que sucede con el -extensísimo-tipo de encouraging/assisting crime $^{66}$, o, ya en el marco concreto del terrorismo, con el de "preparación de actos terroristas", en el que -a la vista de la ambigüedad con que, también aquí, está definido- cabe encajar cualquier acto preparatorio -comprar un mapa o un manual de informática ${ }^{67}$ - de cualquier delito terrorista (pese a lo cual, insisto, tiene prevista la pena de prisión perpetua $)^{68}$.

Desde una perspectiva más amplia, asimismo conviene recordar que esa carrera por combatir la peligrosidad ha traído consigo instrumentos como las preventive orders, que se aplican

63 Sobre el contenido de tales categorías y su delimitación con la de inchoate offences, puede verse ALONSO RIMO, A., “¿Impunidad general....”, cit., pp. 17 y ss.

64 ASHWORTH, A./ZEDNER, L., Preventive Justice, Oxford University Press, Oxford, 2014, pp. 98 y 99.

65 Section 3 Criminal Law Act 1977.

66 Sections 44, 45, 58 Serious Crime Act 2007. Cabe plantear la aplicación de esta figura-según decía, de formulación tan vaga-incluso en referencia a la conspiracy (ayudar para llevar a cabo una conspiración) o igualmente, a la inversa, la punición de la conspiración para incitar o para ayudar a cometer un delito. Vid. sobre el particular, críticamente, ASHWORTH/HORDER, Principles of Criminal Law, $7^{\mathrm{a}} \mathrm{ed}$., Oxford University Press, Oxford, 2013, p. 486. En el $M P C$ estadounidense, según quedó expuesto más arriba, el sistema de punición de los inchoate offences (en este caso: attempt, conspiracy y solicitation) es asimismo abierto - se castigan en relación con el conjunto de las infracciones- y también se homologan por regla general las penas de tales figuras con la de los delitos principales a cuya realización están dirigidas, si bien si estos últimos son muy graves (felonies of the first degree) se prevé una atenuación (vid. supra: nota 29).

67 En la medida en que ello se haga con la intención de cometer o de ayudar a otro a cometer un acto de terrorismo. Son ejemplos que cita ZEDNER, L., "Pre-crime and pre-punishment...", cit., p. 25.

68 Section 5 Terrorism Act 2006. 
en ámbitos muy diversos -las hay relativas a la prevención del terrorismo, de los delitos sexuales o de la delincuencia grave, pero también del indebido uso del espacio público- ${ }^{69}$, o como las diversas modalidades de preventive detention orientadas a neutralizar a los sujetos peligrosos ${ }^{70}$, que comportan importantes restricciones de las libertades y que, como se suele afirmar, constituyen, bajo el ropaje de medidas de carácter administrativo o de internamientos civiles, Derecho penal -cabría añadir: de autor- encubierto ${ }^{71}$.

Resumiendo mucho: que estamos mal; pero que no parece para nada descartable que podamos ir todavía a peor. La experiencia extranjera nos debería servir de advertencia.

69 Las célebres antisocial behaviour orders del derecho inglés, que se imponían por un juez civil para proteger a la ciudadanía de "ulteriores actos antisociales", fueron sustituidas en 2014 por otras preventive orders que responden a ese mismo modelo. En la actualidad, según expone ASHWORTH, existen en el ordenamiento británico más de 20 preventive orders, muchas de las cuales, a juicio del citado autor, otorgan a los tribunales la facultad de configurar una especie de "código penal personalizado" a través de un procedimiento civil y en términos de responsabilidad objetiva, toda vez que permiten aplicar medidas de diversa clase - como por ejemplo la de acudir a determinados lugares- cuyo incumplimiento acarrea penas que generalmente pueden alcanzar hasta los 5 años de prisión y que se imponen -en tal caso ya- por vía penal. En este contexto cabe destacar las Public Spaces Protection Orders, en virtud de las cuales se concede amplia discrecionalidad a las autoridades locales para prohibir determinadas actividades en espacios públicos y que, en opinión de ASHWORTH, suponen de facto dejar en manos de aquéllas la potestad de crear delitos con base en la realización de comportamientos molestos de los que se pueda derivar un efecto perjudicial para la "calidad de vida" de los ciudadanos. ASHWORTH, A., "The Diffusion of Criminal Responsibility: a Cause for Concern?", trabajo inédito facilitado por el autor, pp. 5, 6 y 16. Vid. asimismo, ASHWORTH, A./ZEDNER, L., Preventive Justice, cit., pp. 74 y ss.

70 Vid. ASHWORTH, A./ZEDNER, L., Preventive Justice, cit., pp. 144 y ss.

71 Sobre el carácter crecientemente preventivo del ordenamiento anglosajón en general, puede verse, además de la obra ya citada de ASHWORTH y ZEDNER, RAMSAY, P., The Insecurity State: Vulnerable Autonomy and the Right to Security in the Criminal Law, Oxford University Press, Oxford, 2012; y CARVALHO, H., The Preventive Turn in Criminal Law, Oxford University Press, Oxford, 2017. 


\section{Sobre el fundamento del castigo de la preparación delictiva}

En nuestro ordenamiento hay más Derecho penal de autor del que a primera vista puede parecer. Y la regulación relativa a la criminalización de la preparación delictiva es, con arreglo a lo expuesto hasta aquí, un buen ejemplo de ello. Se ha visto, en efecto, que una parte importante de los tipos de preparación recogidos en la Parte Especial del Código penal, aunque aparecen con la máscara del Derecho penal de la culpabilidad, obedecen realmente al planteamiento de un Derecho penal de la peligrosidad o, mejor, en sentido más amplio, de un Derecho penal de autor. Ello, según se explicaba, por cuanto en los términos en que están conformadas aquellas figuras representan sobre todo una reacción frente al sujeto y su peligrosidad, más allá de su conducta concreta, de tal modo que las consecuencias jurídicas previstas en ellas operan, desde una perspectiva material y por más que formalmente sean penas, como una especie de medidas de seguridad pre-delictuales o pre-castigos.

Nada de eso es aceptable desde el prisma de nuestro marco político-constitucional. En el Derecho penal de un Estado de Derecho la gravedad del hecho debe actuar como fundamento y límite del castigo ${ }^{72}$. Tal y como ha declarado expresamente nuestro Tribunal Constitucional, el de culpabilidad constituye un "principio estructural básico del Derecho penal, de manera que no sería constitucionalmente legítimo un Derecho penal «de autor» que determinara las penas en atención a la personalidad del reo y no según la culpabilidad de éste en la comisión de los hechos (SSTC 65/1986, 14/1988 y otras)"'73. Lo contrario, según

72 Más concretamente, en el sentido en que define GÓMEZ MARTÍN el Derecho penal del hecho, en éste "el objeto de prohibición y de castigo estaría constituido, exclusivamente, por los hechos efectivamente cometidos por humanos que lesionarían o pondrían en peligro bienes jurídicos-penales" (El Derecho penal de autor, Tirant lo Blanch, Valencia, 2007, p. 25).

73 STC 150/1991, de 4 de julio (ponente: Luis López Guerra). Cfr. también las SSTC 159/1985, de 27 de noviembre (ponente: Francisco Rubio Llorente), y 23/1986, de 14 de febrero (ponente: Jerónimo Arozamena Sierra), y el 
ha destacado tradicionalmente la doctrina, autorizaría a castigar con el instrumento más represivo que tiene el Estado conductas que no inciden de manera relevante en la libertad ajena, con el consiguiente menoscabo de la libertad individual -valor superior de nuestro ordenamiento jurídico (art. 1 CE)- y de la dignidad de la persona -fundamento del orden político y de la paz social (art. $10 \mathrm{CE}$ ) ${ }^{74}$. Por aquella vía, además, se corre el riesgo de incurrir en la disolución de la frontera entre Derecho y Moral y de deriva en la persecución ideológica y política ${ }^{75}$. Y tales peligros, como se ha podido comprobar a través de diversos ejemplos en páginas anteriores, no son meramente hipotéticos. Sobre todo este planteamiento -se advierte fácilmente- sobrevuela la imagen del autor despojado de su condición de ciudadano y convertido en enemigo, tratado como mera fuente potencial de delitos que se debe neutralizar ${ }^{76}$. Los delitos de preparación a que se viene haciendo referencia son, en efecto, -también se puede expresar así- Derecho penal del enemigo.

Estoy de acuerdo con ROBINSON en que "(s)i el merecimiento no supone un límite para el sistema de justicia penal, entonces la responsabilidad y la pena se pueden distribuir de cualquier forma que el cálculo preventivo sugiera que reducirá

análisis que de las mismas realiza VIVES ANTÓN ("Constitución y medidas de seguridad", en EL MISMO, La libertad como pretexto, Tirant lo Blanch, Valencia, 1995, pp. 245 y ss.).

74 “«La libertad», dice el art. $4^{\circ}$ de la Declaración de los Derechos del Hombre y del Ciudadano de 1789, «consiste en poder hacer todo lo que no daña a los demás»". Por ello, explica FERRAJOLI, "se pueden configurar como delictivas, en garantía al mismo tiempo de las libertades y de la igual dignidad de las personas, solamente las acciones nocivas y no los sujetos nocivos" (El paradigma garantista. Filosofia crítica del Derecho penal, Trotta, 2018, p. 115).

75 Cfr. RODRÍGUEZ MOURULLO, G., "La punición...”, cit., pp. 288 y ss.

76 Vid. por todos, resaltando que el Derecho del enemigo es "ante todo el Derecho de las medidas de seguridad aplicables a imputables peligrosos", y ello aun cuando tales medidas se muestren en ocasiones "bajo la apariencia formal de penas", SILVA SÁNCHEZ, J. M., La expansión ..., cit., pp. 185 y 186; y asimismo, llamando la atención sobre el estrecho vínculo -“estructural"- entre Derecho penal de autor y Derecho penal del enemigo, CANCIO MELIÁ, M., "De nuevo...”, cit., pp. 137-139. 
el delito"77. Es decir, que una vez rebasado ese límite, en nombre de la prevención y de la seguridad de la comunidad, se puede aceptar cualquier cosa (por ejemplo: castigar una conspiración para delinquir o cualquier otro acto preparatorio -en general, indefinido- dirigido a cometer un acto terrorista con pena de prisión perpetua $\left.{ }^{78}\right)$. La experiencia histórica ${ }^{79}$ pero también la

77 Principios..., cit., 143. En un orden de ideas similar, señala PUSCHKE que “(e)n relación con la punición, se plantea cada vez en menor medida la pregunta acerca de si una determinada conducta puede ser considerada lesiva socialmente e intolerable para una convivencia ordenada entre las personas. La pregunta es, cada vez más a menudo, si con la criminalización de una conducta determinada puede evitarse otra conducta que se considera lesiva desde la perspectiva social. La valoración de lo injusto es sustituida por una valoración de la efectividad y los límites de lo que ha de constituir una conducta susceptible de ser penada se tornan movedizos". Como asimismo destaca el citado autor, y en el sentido en que se viene indicando, ésa es claramente la perspectiva que predomina en los delitos preparatorios -cabría matizar, mejor, en la parte de los delitos preparatorios que responden al modelo descrito en líneas anteriores-, en los que se trata, más que de incidir en el plano psicológico para evitar la comisión en general de esa clase de conductas, de evitar "un curso de acontecimientos determinado", a modo de un "Derecho penal de la intervención" de marcado carácter policial, con el consiguiente desplazamiento de los criterios para determinar la punibilidad al terreno de la efectividad y de lo fáctico (“Origen...”, cit., p. 14). JAKOBS habla también, en esa línea, de "argumentos preventivos-policiales" -entre otros- para explicar la extendida disposición en el ámbito alemán a aceptar "anticipaciones de la punibilidad", entre las que incluye de manera señalada los tipos de preparación: "Se anticipa la consumación para conceder a la policía la posibilidad de intervenir en el momento propicio para hacerlo; pues con la anticipación de la punibilidad se amplían los límites de lo permitido para la prevención en la medida de lo permitido para la represión" ("Criminalización...”, cit., p. 294). Una orientación similar se advierte también en algunas de las razones que, a juicio de los redactores del MPC estadounidense, permiten justificar la punición de los inchoate offences (AMERICAN LAW INSTITUTE, Model Penal..., cit., p. 294).

78 Vid. supra: epígrafe 4.1.

79 Vid. MUÑOZ CONDE, F., Edmund Mezger y el Derecho penal de su tiempo. Estudios sobre el Derecho penal en el Nacionalsocialismo, $4^{\mathrm{a}}$ ed., Tirant lo Blanch, Valencia, 2003; GÓMEZ MARTÍN, V., El Derecho penal..., cit., pp. 115 y ss.; PORTILLA CONTRERAS, G., La consagración del derecho penal de autor durante el franquismo. El Tribunal especial para la represión de la masonería y el comunismo, Comares, Granada, 2009; LLOBET 
evolución actual del Derecho penal, en la línea de lo que se viene exponiendo, lo corrobora ${ }^{80}$.

\subsection{Actos preparatorios y principio del hecho}

Lo hasta aquí concluido -gran parte de los actos preparatorios tipificados en nuestro derecho positivo constituyen tan palmarias como censurables manifestaciones de un Derecho penal de autor, con todos los riesgos que ello implica desde el punto de vista de las garantías de un Estado de Derecho- no responde a la cuestión de si, tal y como ha sostenido parte de la doctrina, toda criminalización de la preparación delictiva vulnera el principio del hecho y resulta, en consecuencia, ilegítima ${ }^{81}$. A mi juicio, la respuesta a esta cuestión debe ser negativa.

Descartadas, con base en las razones ya explicadas, las tesis subjetivas $-\mathrm{y}$ sus sucedáneas- $\mathrm{y}$ asimismo las que ven en

RODRÍGUEZ, J., Nacionalsocialismo y antigarantismo penal (1933-1945), Tirant lo Blanch, Valencia, 2018.

80 Vid., desde una perspectiva más amplia, el trabajo de VIVES ANTÓN, denunciando que "(1)as ideas nacionalsocialistas (...) perviven aún, tanto en Alemania como en España" y citando como ejemplo de ello el adelantamiento de la línea de defensa penal al que asistimos, que define como "un proceso abierto, que actualmente bascula sobre la sustitución de la culpabilidad por la peligrosidad y de la pena por la medida" ("Segundo seminario: nullum crimen sine lege. Comisión por omisión y dogmática penal”, en EL MISMO/CUERDA/GÓRRIZ (eds.), Acción significativa, comisión por omisión y dogmática penal, Tirant lo Blanch, Valencia, 2017, pp. 218 y ss., p. 223). Y asimismo, en referencia específica a los delitos de terrorismo y al discurso del odio, VIVES ANTÓN, T.S., "Garantías constitucionales y terrorismo", en ALONSO/ CUERDA/FERNÁNDEZ (dirs.), Terrorismo, sistema penal y derechos fundamentales, Tirant lo Blanch, Valencia, 2018, pp. 29 y ss.

81 RODRÍGUEZ MOURULLO, G., "La punición...”, cit., p. 292; JAKOBS, G., "Criminalización...", cit., pp. 298 y ss. y 305 y ss. Cfr. también CANCIO MELIÁ, M., en LASCURAÍN SÁNCHEZ (coord.), Introducción..., cit., p. 94; y asimismo, poniendo el acento sobre todo en la conculcación del principio de ofensividad que su punición supone, entre otros, GONZÁLEZ CUSSAC, J. L., "Principio de ofensividad, aplicación del Derecho y reforma penal", en Poder Judicial, (28), 1992, pp. 28, 34; FUENTES OSORIO, J. L., La preparación delictiva, Comares, Granada, 2007, pp. 53 y ss.; EL MISMO, "Formas de anticipación de la tutela penal", Revista Electrónica de Ciencia Penal y Criminología, 08-08, 2006, p. 12. 
la peligrosidad del autor el fundamento del castigo de los actos preparatorios, creo que es posible justificar tal punición en términos objetivos, en atención al peligro representado por la conducta de preparación para el bien jurídico del delito principal, y sin que esto implique un vaciamiento del contenido del principio del hecho ni de la denominada esfera privada del ciudadano. A estos efectos se ha de partir de una premisa que, aun siendo quizás obvia, resulta fundamental en el contexto de esta discusión: la tipificación de actos preparatorios debe sujetarse de manera muy estricta al cumplimiento de los principios de ofensividad y de prohibición de exceso o proporcionalidad en sentido amplio, con los que el principio del hecho, según se ha podido comprobar en páginas anteriores, se halla tan estrechamente imbricado.

El principio del hecho no puede, en efecto, limitarse a requerir la exteriorización de un hecho cualquiera ${ }^{82}$. Tal exigencia es verdad que excluiría la punición de los pensamientos no exteriorizados o "el castigo directo de actitudes internas" $"$, lo que sin duda sería Derecho penal de autor. Pero hemos comprobado que también se hace Derecho penal de autor cuando se sanciona un hecho externo inocuo (vulneración del principio de ofensividad) o no lo suficientemente ofensivo como para ser objeto de castigo penal (vulneración del principio de necesidad) buscándose en realidad criminalizar la actitud interna, o igualmente cuando se trata de un hecho externo que, reuniendo ese contenido mínimo exigible de lesividad, tiene asignada una pena superior a la que resultaría ajustada a la gravedad del hecho (vulneración del principio de proporcionalidad) y ello se hace, asimismo aquí, por razones que tienen que ver con la peligrosidad del autor, con su forma de ser o, en fin, con el colectivo en el que se integra. En todos esos casos, y hemos visto a lo largo del trabajo algunos ejemplos concretos de tipos preparatorios en que ello sucede así, se utiliza entonces el hecho externo como mero subterfugio para castigar autores peligrosos (no he-

\footnotetext{
82 Se trataría en ese caso, como indica PAWLIK, de una concepción del principio del hecho meramente formal (Der Terrorist..., cit., pp. 26 y 27).

83 COBO DEL ROSAL, M./VIVES ANTÓN, T. S., Derecho penal..., cit., p. 343.
} 
chos peligrosos). Como señalan COBO DEL ROSAL y VIVES ANTÓN, cuando la Constitución establece en su art. 25.1 que "nadie puede ser condenado por acciones u omisiones que en el momento de producirse no constituyen delito" no se contenta "con la exigencia de un hecho sino que requiere que la condena sea por ese hecho externo, excluyendo la posibilidad de que el hecho sea utilizado como un simple pretexto para reprimir situaciones o condiciones anímicas" $"$.

De acuerdo con todo lo anterior, no resultaría aceptable desde luego penar acciones preparatorias de las que se derivara un peligro meramente remoto o insignificante para el bien jurídico. Por el contrario, se requerirían a tal efecto actuaciones que generaran un notable incremento de las probabilidades de comisión del delito-fin, y aun así se podrían sancionar únicamente en los casos de los delitos-fin más graves y con una pena proporcionada a la gravedad de la conducta preparatoria concreta llevada a cabo. La regla habría de ser entonces, sin duda, la impunidad de los actos preparatorios; pues por tratarse de comportamientos previos en todo caso al inicio del ejecución del delito-fin y tan alejados en general del ataque al bien jurídico, lo normal será que no reúnan el necesario grado de lesividad-que, en los términos explicados, imponen los principios de ofensividad y de prohibición de exceso- y castigarlos, por consiguiente, vulnerará habitualmente, además de éstos, también el principio del hecho ${ }^{85}$. Ahora bien,

84 Cursiva en el original. Derecho penal..., cit., pp. 344 y 345. Cfr. también ORTS BERENGUER, E./GONZÁLEZ CUSSAC, J.L., Compendio de Derecho penal, Parte General, $7^{\mathrm{a}}$ ed., Tirant lo Blanch, Valencia, 2017, pp. 149 y 150.

85 Lo afirmado no quiere decir, tal y como yo lo veo, que toda lesión del principio de ofensividad o del de proporcionalidad implique hacer Derecho penal de autor. Puede ser que el castigo de conductas no ofensivas o con penas desproporcionadas, y el consiguiente desbordamiento de los límites impuestos por la gravedad del hecho, se deba a razones de prevención general (como sucede, entre otros casos, en los delitos acumulativos). Aquí creo que cabría hablar de un Derecho penal puramente preventivo (en tanto que orientado a la prevención sin límites), que implicaría también una quiebra de la responsabilidad por el hecho, en la medida en que se sanciona al sujeto más allá del hecho concreto por él cometido; pero en este caso la vulneración del principio del hecho no se traduciría en Derecho penal de autor. 
toda vez que un determinada conducta preparatoria sí satisfaga tal requisito y que su tipificación se ajuste a los parámetros indicados -se limite al supuesto que comporta un peligro relevante en los términos señalados, en referencia a un delito principal de los más graves y se conmine con pena proporcionada-su sanción sí sería, en abstracto, legítima, dado que se estaría penando (solo) ese hecho específico, en la medida del daño social (peligro) por él generado. Es decir, la pena en tal caso se fundamentaría en el hecho concreto ya cometido y no en el hecho futuro que el sujeto (preparador) quería realizar, o que otros realizaran, en un momento ulterior.

Los criterios que podrían autorizar -bajo esa estricta óptica- la punición de actos preparatorios, y que habrían de operar con independencia de si los tipos de preparación están definidos en la Parte General o en la Parte Especial del Código penal, son susceptibles -y están, de hecho, necesitados- de una concreción mucho mayor de la hasta aquí realizada y que en el marco de este trabajo no se puede acometer. Con todo, añadiré a continuación algún ejemplo a fin de tratar de ofrecer una noción algo más precisa de la concepción que aquí se mantiene. Creo, de acuerdo con la mayoría de la doctrina y también -por lo que se me alcanza- de los legisladores de los ordenamientos de nuestro entorno jurídico-cultural, que en referencia a los actos preparatorios de los arts. 17 y $18 \mathrm{del} \mathrm{CP}$ es posible hablar de un riesgo -derivado, según asimismo opinión común, de la implicación de otros sujetos en el proyecto criminal ${ }^{86}$ - que, aunque mediato ${ }^{87}$, puede adquirir significación suficiente a efectos de que quepa,

86 Y, más concretamente, de la sinergia de voluntades de las diversas personas involucradas y de la puesta en marcha de procesos causales delictivos mediante la captación de voluntades. Vid. MIR PUIG, S., Derecho penal. Parte general, $10^{\mathrm{a}}$ ed., Reppertor, Barcelona, 2016, pp. 350 y 351; DÍAZ Y GARCÍA CONLLEDO, M., “Conspiración...”, cit., pp. 301 y 302.

87 Como siempre sucede en los actos preparatorios, que no pueden, directamente o por sí mismos, dañar el bien jurídico sino que a tal fin necesitan en todo caso una conducta ulterior (intermedia); la que integra el delito principal o de referencia. 
en principio, plantearse su castigo penal. Y que, en concordancia con lo expuesto, y dado que el fundamento de dicha sanción ha de residir precisamente en la peligrosidad objetiva -en términos de sensible aumento de las posibilidades de consumación de un delito-fin determinado- de la conducta preparatoria concretamente llevada a cabo, habrá de exigirse a tal efecto, como en general se suele aceptar, y entre otros requisitos, la firme voluntad del preparador o preparadores dirigida a la consumación de aquel ilícito, la idoneidad del plan trazado en la conspiración o la suficiente aptitud suasoria de la incitación en los casos de la proposición y de la provocación. En la misma línea, y aunque en cuanto a esto el consenso es ya menor, se requeriría la aceptación de la propuesta en la proposición -en cualquiera de sus modalidades- y descartar en todo caso la punición de la incitación en cadena y de las apologías -tanto de la homologable a la provocación directa del art. 18 como de las diversas variantes de apologías débiles que pueblan la Parte Especial de nuestro Código penal-; lo mismo que, en un plano más general, una restricción mucho más exigente del círculo de delitos-fin que admiten el castigo de las tres figuras preparatorias y una rebaja de las penas, que habrían de resultar necesariamente inferiores a las de la tentativa. La regulación vigente sobre el particular tendría que ser, pues, objeto de una importante reformulación, justamente en la dirección opuesta a la de la reforma penal de 2015, que como es sabido extiende la criminalización de tales conductas al numeroso catálogo de los delitos contra la Administración Pública, amplía la definición legal de proposición del art. $17 \mathrm{CP}$ y, en fin, introduce en el Libro II nuevos delitos apologéticos -y no solo en el ámbito del terrorismo-y tipos que admiten abiertamente la sanción de la preparación de la preparación.

Vistas las cosas de esta manera, no creo que pueda decirse que el principio del hecho, y con él el conjunto de principios que el mismo arrastra, carezca de cualquier virtualidad limitadora ${ }^{88}$.

88 JAKOBS parte de la base de que el principio de protección de bienes jurídicos no conoce límites, que permite anticipar potencialmente sin restricción 
Por lo demás, que con arreglo a lo razonado haya (un limitado) margen para la legitimidad del castigo de los actos preparatorios, que en determinados supuestos muy concretos pueda justificarse su punición, no implica -es importante remarcarlo-

alguna el comienzo del peligro para el bien jurídico, de modo que, desde esta perspectiva, la esfera privada del ciudadano y el principio del hecho quedan vacíos de contenido ("Criminalización...", cit., p. 295). Ello le lleva a defender, en aras de salvaguardar esa "esfera civil interna" del ciudadano, que la frontera a partir de la cual resulta posible plantear la exigencia de responsabilidad penal deba retrasarse con carácter general hasta la existencia de conductas externas que son ya en sí mismas perturbadoras - es decir, que puedan ser entendidas como una perturbación con independencia de la parte subjetiva y en general del comportamiento del autor en su ámbito privado (ibidem, pp. 297 y ss.)-, y a partir de ahí, en lo que ahora más interesa y asimismo sobre las bases apuntadas, a rechazar en su práctica totalidad (con solo alguna excepción muy puntual) la criminalización de los actos preparatorios -"en su cualidad" de tales- y a calificar los preceptos que contemplan tales tipificaciones como Derecho penal del enemigo (pp. 298 y ss., 305 y ss.). No me es posible entrar ahora, en el marco de este trabajo, a analizar con detalle la posición mantenida a este respecto por el profesor de Bonn, ni las diversas y ricas observaciones que formula sobre esta importante problemática (la tormentosa vigencia del principio del hecho). Desde mi concepción, en el sentido explicado en el texto, los principios de ofensividad y, en particular, el de proporcionalidad en sentido amplio -a los que aparece de manera indisolublemente ligada el principio del hecho- imponen una considerable restricción del ámbito de lo punible y no permiten castigar cualquier peligro para el bien jurídico, por remoto que sea, derivado de un hecho externo. Estimo que ello lo muestra el análisis realizado en páginas anteriores, dirigido a denunciar la existencia de figuras delictivas preparatorias en nuestro derecho vigente que, precisamente por no cumplir dichos estándares, admiten ser consideradas como formas de ilegítimo Derecho penal de autor; y que la misma conclusión se sigue de los resultados a los que, partiendo de los presupuestos más arriba indicados, se llega en este trabajo en lo que respecta al (restringido) espacio a otorgar al castigo penal de los actos preparatorios en general. Pero lo que sobre todo quisiera destacar ahora, y sin perjuicio de lo anterior, es que, aun cuando JAKOBS se guía a priori por el encomiable propósito de otorgar mayor relevancia al principio del hecho y de contraer el ámbito de criminalización en beneficio de la esfera de privacidad del ciudadano, lo cierto es que a la vez, por la vía de admitir paralelamente la legitimidad de normas de flanqueo -cuya misión es garantizar la "seguridad cognitiva" o "las condiciones de vigencia de las normas principales"- y de la tutela de bienes jurídicos, como la paz 
que ello sea una opción político-criminal aconsejable. Es decir: pese a lo anterior e incluso en lo que se refiere a ese estricto margen podrían seguir existiendo razones atendibles a favor de su impunidad ${ }^{89}$.

jurídica o la paz pública, situados delante -en los flancos- de aquellos otros que se dirigen a la lesionar los comportamientos preparatorios (ibidem, pp. 313 y ss.), llega a algunos resultados que apuntan en una dirección contraria al objetivo general al que declaradamente apunta en principio el autor de limitar el ámbito de criminalización y de dotar, con ello, de mayor consistencia al principio del hecho. Así, por un lado, se acaba derivando de facto, respecto de esos concretos supuestos cuyo injusto considera susceptible de fragmentación, una ampliación de su marco de tipicidad. Ejemplo: en el caso de la provocación (en referencia aquí al tipo del § 111 StGB), el verbo típico, provocar, según admite JAKOBS, "no tiene que ser interpretado de un modo tan estricto como el «determinar» de la inducción" (ibidem, p. 317, nota 33); lo cual, desde su concepción, es de todo punto lógico, pues no se trata ya de una conducta cuyo injusto se cifre en el incremento de las posibilidades de comisión del delito-fin y en relación con la cual resulte necesario, por consiguiente, valorar si es lo suficientemente suasoria a tal efecto. Se trata aquí, por el contrario, de una responsabilidad "por la publicación y, en consecuencia, por el efecto amenazante de su comportamiento" (ibidem, p. 317) o que, desde una perspectiva más general, se justifica por cuanto el comportamiento incide, en términos similares a como sucede en el injusto de las amenazas entendidas como delitos contra la paz jurídica, en la base cognitiva de la confianza en la norma (ibidem, p. 315). Por otro lado, y en un plano de importancia mayor, a la vista de todo lo anterior cabe preguntarse, como observa SILVA SÁNCHEZ, hasta qué punto lo prohibido en las citadas normas de flanqueo son "hechos" y no meros "pronósticos de peligrosidad" o estados peligrosos ("La «intervención» a través de organización, ¿una forma moderna de participación en el delito?", en CANCIO MELIÁ/ SILVA SÁNCHEZ, Delitos de organización, B de F., Montevideo - Buenos Aires, 2008, p. 92). En este punto creo que es importante resaltar que la defensa de la existencia de normas de flanqueo, en los términos expuestos, la realiza JAKOBS ¡en el marco del Derecho penal del ciudadano! (en el del Derecho penal del enemigo, como es sabido, la asunción de la peligrosidad del autor como fundamento de la intervención punitiva resulta ya manifiestamente admitida).

89 Aunque, nuevamente, el análisis de la cuestión no puede ser objeto de atención en estas páginas. Vid. aludiendo a algunos de dichos argumentos -por ejemplo, que la impunidad de los actos preparatorios fomenta el desistimiento, la problemática que se plantea en torno a la equivocidad de tal clase de conductas o el necesario respeto que se debe otorgar en una sociedad democrática a la autonomía del individuo-, ORTS BERENGUER, E., 


\section{6. ¿Derecho penal de excepción?}

Sería equivocado pensar, advertía RODRÍGUEZ MOURULLO en el año 1968, que el "problema político" que subyace a la cuestión de la incriminación de los actos preparatorios "representa una típica preocupación del liberalismo decimonónico, que debe considerarse hoy superada" ${ }^{\circ 0}$. Lo expuesto a lo largo de este trabajo evidencia que las palabras del citado autor conservan, 50 años después de que las escribiera, plena vigencia.

Y ello no solo por lo que se refiere a nuestro ordenamiento. La creciente inclinación a expandir la criminalización al estadio de la preparación delictiva no es algo privativo del sistema español. Hemos podido constatar en páginas anteriores que se aprecia también en el ordenamiento británico y en el italiano, y que la regulación del $M P C$ estadounidense conecta igualmente con esa orientación. La misma conclusión se alcanza -se trata de una tendencia en claro avance- si se atiende a la legislación alemana $^{91} \mathrm{o}$ a la normativa europea ${ }^{92}$.

El panorama descrito en cuanto a la tipificación de los actos preparatorios creo que ilustra bien el Derecho penal hacia el que, desde una perspectiva más general, avanzamos (?) -0, mejor, nos dirigimos-: de autor, de carácter preventivo-fáctico y policial, insaciablemente expansivo, no sólo en un plano horizontal, sino también, como destaca ASHWORTH, en un sentido

“Consideraciones...”, cit., p. 490; DÍEZ RIPOLLÉS, J. L., Derecho penal español. Parte general, 4a ed., Tirant lo Blanch, Valencia, 2016, pp. 516 y 517; DUFF, R. A., "Criminalizing Endangerment”, en Louisiana Law Review, 65, 7, 2005, p. 964.

90 "La punición...", cit., p. 289, en alusión a la incriminación genérica de la conspiración, la proposición y provocación que contemplaba el Código penal anterior.

91 Vid. PETZSCHE, A., "Punishability of Preparatory Acts in German Criminal Law“, en SINN (Hrsg.), Menschenrechte und Strafrecht - Beiträge zur 4. Sitzung des International Forum on Crime and Criminal Law in the Global Era (IFCCLGE), 2013, pp. 67 y ss.; PUSCHKE, J., “Origen...”, cit., pp. 5 y ss.

92 Vid. Directiva (UE) 2017/541 del Parlamento Europeo y del Consejo de 15 de marzo de 2017 relativa a la lucha contra el terrorismo. 
vertical, que va añadiendo nuevas capas (layers) de responsabilidad criminal ${ }^{93}$; que, en fin, está regido primariamente por la idea de prevención sin límites. Lo que ahora quisiera sobre todo destacar, ya para acabar, es que no se trata como resulta fácilmente apreciable de un modelo de excepción, que se restrinja al delincuente habitual o permanente -incorregible-, ni a terroristas o depredadores sexuales, sino que alcanza también a manifestantes alborotadores, twitteros y raperos provocadores de mal gusto, estafadores, o falsificadores de poca monta, ninguno de los cuales es necesario ni siquiera que sean reincidentes a fin de que sea posible sancionarlos con base en razones de mera peligrosidad subjetiva $-\mathrm{y}$, como hemos visto, presunta $-\mathrm{y}$ con penas en algunos casos muy serias.

\section{Bibliografía citada}

ALONSO RIMO, A., "Los nuevos delitos de ¿desórdenes? ¿públicos? Especial referencia a los tipos de incitación o de refuerzo de la disposición a delinquir (arts. 557.2 y 559 CP)", Estudios Penales y Criminológicos, 35, 2015.

ALONSO RIMO, A., “¿Impunidad general de los actos preparatorios? La expansión de los delitos de preparación”, InDret. Revista para el análisis del Derecho, 4, 2017.

93 “A new generation of omissions offences?", en Criminal Law Review, 2018, pp. 1-2, 5 y 9. Cfr. también GONZÁLEZ CUSSAC, que habla de un "Derecho penal híbrido", que se rige por la política criminal del pensamiento neoconservador y en el que la anticipación se erige en criterio rector, con la consiguiente afectación a principios esenciales del Estado de Derecho como, entre otros, el del hecho o el de ofensividad ("Apuntes de un Derecho penal híbrido", en SILVA/QUERALT/CORCOY/CASTIÑEIRA (coords.), Estudios de Derecho penal. Homenaje al profesor Santiago Mir Puig, B de F, Montevideo, 2017, pp. 92-101); y BORJA JIMÉNEZ, llamando la atención sobre la conexión de estos rasgos, y en general de las tendencias político criminales dominantes, con la ideología de la globalización ("Justicia penal preventiva y Derecho penal de la globalización: proyecciones en el ámbito del terrorismo", en ALONSO/CUERDA/FERNÁNDEZ (dirs.), Terrorismo, sistema penal y derechos fundamentales, Tirant lo blanch, Valencia, 2018, pp. 167 y ss. 
AMERICAN LAW INSTITUTE, Model Penal Code and Commentaries (Official Draft and Revised Comments), Part I, 1985.

ASHWORTH, A., "Attempts», en DEIGH/DOLINKO (eds.), The Oxford Handbook of Philosophy of Criminal Law, Oxford Handbooks Online, 2011.

ASHWORTH, A., "A new generation of omissions offences?", Criminal Law Review, London, 2018.

ASHWORTH, A., "The Diffusion of Criminal Responsibility: a Cause for Concern?", trabajo inédito.

ASHWORTH/HORDER, Principles of Criminal Law, $7^{\mathrm{a} e d}$, Oxford University Press, Oxford, 2013.

ASHWORTH, A./ZEDNER, L., Preventive Justice, Oxford University Press, Oxford, 2014.

BARBER BURUSCO, S., "Del delito de "difusión" o "propaganda" terrorista a la desmesurada expansión de la punición de actos preparatorios", Cuadernos de Política Criminal, 116-2, 2015.

BELLOCH JULBE, J. A., "Contemplación jurisprudencial sobre el binomio libertad de información terrorismo: la apología del terrorismo", en Estudios jurídicos en honor de J. Gabaldón López, Trivium, Madrid, 1990.

BOLDOVA PASAMAR, M. A., "Consecuencias sancionadoras de la radicalización terrorista de los menores de edad y su adecuación al perfil de jóvenes infractores", en ALONSO/CUERDA/FERNÁNDEZ (dirs.), Terrorismo, sistema penal y derechos fundamentales, Tirant lo Blanch, Valencia, 2018.

BORJA JIMÉNEZ, E., “Justicia penal preventiva y Derecho penal de la globalización: proyecciones en el ámbito del terrorismo", en ALONSO/CUERDA/FERNÁNDEZ (dirs.), Terrorismo, sistema penal y derechos fundamentales, Tirant lo blanch, Valencia, 2018.

BUSTOS RAMÍREZ, J., Lecciones de Derecho penal. Parte General, Trotta, Madrid, 2006. 
CANCIO MELIÁ, M., “De nuevo: ¿«Derecho penal» del enemigo?", en JAKOBS/CANCIO, Derecho penal del enemigo, $2^{\text {a }}$ ed., Thomson-Civitas, Madrid, 2006.

CANCIO MELIÁ, M., en LASCURAIIN SÁNCHEZ (coord.), Introducción al Derecho penal, $2^{\mathrm{a}}$ ed., Thomson-Civitas, Pamplona, 2015.

CANCIO MELIÁ, M., "El concepto jurídico-penal de terrorismo entre la negación y la resignación", en ALONSO/ CUERDA/FERNÁNDEZ (dirs.), Terrorismo, sistema penal y derechos fundamentales, Tirant lo Blanch, Valencia, 2018.

CARBONELL MATEU, J. C., "Crítica a los sentimientos como bien jurídico-penal: el enaltecimiento del terrorismo y la humillación a las víctimas «más allá de la provocación y la injuria»", en ALONSO/CUERDA/FERNÁNDEZ (dirs.), Terrorismo, sistema penal y derechos fundamentales, Tirant lo Blanch, Valencia, 2018.

CARVAlHO, H., The Preventive Turn in Criminal Law, Oxford University Press, Oxford, 2017

COBO DEL ROSAL, M./VIVES ANTÓN, T. S., Derecho penal. Parte General, $5^{\mathrm{a}}$ ed., Tirant lo Blanch, Valencia, 1999.

CUERDAARNAU, M. L., "Nos queda la palabra: contra la nueva orientación político-criminal en materia de orden público", en VVAA. (dirs.), Crímenes y Castigos. Miradas al Derecho penal a través del arte y la cultura, Tirant lo Blanch, Valencia, 2014.

CUERDA ARNAU, M. L., "Adoctrinamiento de jóvenes terroristas y sistema penal", en VVAA, Liber Amicorum. Estudios en Homenaje al Prof. Dr. Dr.h.c. Juan $M^{a}$ Terradillos Basoco, Tirant lo Blanch, Valencia, 2018.

DÍAZ Y GARCÍA CONLLEDO, M., "Conspiración, proposición y provocación”, en LUZÓN PEÑA (dir.), Enciclopedia Penal Básica, Comares, Granada, 2002.

DÍEZ RIPOLLÉS, J. L., Derecho penal español. Parte general, $4^{\mathrm{a}}$ ed., Tirant lo Blanch, Valencia, 2016.

DUFF, R. A., "Criminalizing Endangerment", Louisiana Law Review, 65, 7, 2005. 
FERRAJOLI, L., El paradigma garantista. Filosofía crítica del Derecho penal, Trotta, Madrid, 2018.

FRONZA, E., "Tutela penal anticipada y normativa antiterrorismo en el ordenamiento italiano", en AMBOS/MALARINO/STEINER (eds.), Terrorismo y Derecho penal, Konrad-Adenauer-Stiftung, Berlín, 2015.

FUENTES OSORIO, J. L., La preparación delictiva, Comares, Granada, 2007.

FUENTES OSORIO, J.L. "Formas de anticipación de la tutela penal", Revista Electrónica de Ciencia Penal y Criminología, 08-08, 2006.

GALÁN MUÑOZ, A., "Leyes que matan ideas frente a las ideas que matan personas? Problemas de la nueva represión de los mecanismos de captación terrorista tras la reforma del Código penal de la LO 2/2015", Revista de Derecho penal y Criminología, $3^{\mathrm{a}}$ Época, $\mathrm{n}^{\mathrm{o}} 15$ (enero de 2016).

GÓMEZ MARTÍN, V., El Derecho penal de autor, Tirant lo Blanch, Valencia, 2007.

GONZÁLEZ CUSSAC, J.L., "Principio de ofensividad, aplicación del Derecho y reforma penal", en Poder Judicial, (28), 1992.

GONZÁLEZ CUSSAC, J.L., "Apuntes de un Derecho penal híbrido", SILVA/QUERALT/CORCOY/CASTIÑEIRA (coords.), Estudios de Derecho penal. Homenaje al profesor Santiago Mir Puig, B de F, Montevideo, 2017.

HUSAK, D., "Lifting the Cloak: Preventive Detention as Punishment", 48 San Diego Law Review, 2011.

JAKOBS, G., "Criminalización en el estado previo a la lesión de un bien jurídico", trad. Peñaranda Ramos, en EL MISMO, Estudios de Derecho penal, Civitas, Madrid, 1997.

JAKOBS, G., “¿Terroristas como personas en Derecho?”, trad. M. Cancio Meliá, en JAKOBS/CANCIO, Derecho penal del enemigo, Thomson-Civitas, Madrid, 2006.

JIMÉNEZ DE ASÚA, L., La ley y el delito, Losada, Buenos Aires, 1954, p. 502.

LLOBET RODRÍGUEZ, J., Nacionalsocialismo y antigarantismo penal (1933-1945), Tirant lo Blanch, Valencia, 2018. 
LOEWY, A. H., Criminal Law in a nutshell, $5^{\mathrm{a}}$ ed., West, Saint Paul, 2009.

MAQUEDA ABREU, M. L., "La criminalización del espacio público. El imparable ascenso de las «clases peligrosas»", Revista Electrónica de Ciencia Penal y Criminología, 17-12, 2015.

MARTÍNEZ GARAY, L., "La incertidumbre de los pronósticos de peligrosidad. Consecuencias para la dogmática de las medidas de seguridad", InDret. Revista para el análisis del Derecho, 2, 2014.

MARTÍNEZ GARAY, L., "Errores conceptuales en la estimación de riesgo de reincidencia. La importancia de diferenciar sensibilidad y valor predictivo, y estimaciones de riesgo absolutas y relativas", Revista Española de Investigación Criminológica, $\mathrm{n}^{\circ} 14$ (2016).

MARTÍNEZ GARAY, L./MONTES SUAY, F., "El uso de valoraciones del riesgo de violencia en Derecho Penal: algunas cautelas necesarias", InDret. Revista para el análisis del Derecho, n 2/2018.

MARTUFI, A., "Nulla periculositas sine actione? Pericolosità sociale e materialità del fatto alla prova delle fattispecie di quasi reato", Rivista Italiana di Diritto e Procedura Penale, Vol. 58, n 2, 2015.

MIR PUIG, S., Derecho penal. Parte general, $10^{\mathrm{a}}$ ed., Reppertor, Barcelona, 2016.

MIRA BENAVENT, J., “Algunas consideraciones político-criminales sobre la función de los delitos de enaltecimiento del terrorismo y humillación a las víctimas del terrorismo", en PORTILLA CONTRERAS/PÉREZ CEPEDA (dirs.), Terrorismo y contraterrorismo en el Siglo XXI. Un análisis penal y político criminal, Ratio Legis, Salamanca, 2016.

MIRA BENAVENT, J., "El delito de enaltecimiento del terrorismo, el de humillación a las víctimas del terrorismo y la competencia de la Audiencia Nacional: ni delito, ni terrorismo, ni competencia de la Audiencia Nacional", 
en ALONSO/CUERDA/FERNÁNDEZ (dirs.), Terrorismo, sistema penal y derechos fundamentales, Tirant lo Blanch, Valencia, 2018.

MUÑAGORRI LAGUÍA, I., "Punición o despenalización de la proposición para delinquir", Anuario de Derecho penal y Ciencias penales, T. 42, Fasc. 3, 1989.

MUÑOZ CONDE, F., Edmund Mezger y el Derecho penal de su tiempo. Estudios sobre el Derecho penal en el Nacionalsocialismo, $4^{\mathrm{a}}$ ed., Tirant lo Blanch, Valencia, 2003.

NOTARO, D., “Art. 202”, en PADOVANI, Codice Penale, T. I, VI ed., Giuffrè, Milano, 2014.

ORTS BERENGUER, E., "Consideraciones sobre la fase interna y los actos preparatorios del delito", Cuadernos de Política Criminal, 18, 1982.

ORTS BERENGUER, E./GONZÁLEZ CUSSAC, J.L., Compendio de Derecho penal, Parte General, $7^{\mathrm{a}}$ ed., Tirant lo Blanch, Valencia, 2017.

PAWLIK, M., Der Terrorist und sein Recht. Zur rechtstheoretischen Einordnung des modernen Terrorismus, C. H. Beck, Múnich, 2008.

PETZSCHE, A., "Punishability of Preparatory Acts in German Criminal Law», en SINN (Hrsg.), Menschenrechte und Strafrecht - Beiträge zur 4. Sitzung des International Forum on Crime and Criminal Law in the Global Era (IFCCLGE), 2013.

PORTILLA CONTRERAS, G., La consagración del derecho penal de autor durante el franquismo. El Tribunal especial para la represión de la masonería y el comunismo, Comares, Granada, 2009.

PORTILLA CONTRERAS, G., "La contrarrevolución preventiva emprendida por el Derecho penal y administrativo para hacer frente a los movimientos de protesta y desobediencia civil", en CUERDA ARNAU/GARCÍA AMADO (dirs.), Protección jurídica del orden público, la paz pública y la seguridad ciudadana, Tirant lo Blanch, Valencia, 2016.

PUENTE RODRÍGUEZ, L., "La punición del autoadoctrinamiento terrorista: breve pasado y ¿breve futuro?”, en PÉ- 
REZ CEPEDA (dir.), Actas del seminario internacional El terrorismo en la actualidad: un nuevo enfoque político criminal, Ratio legis, Salamanca, 2017.

PUSCHKE, J., "Origen, esencia y límites de los tipos penales que elevan actos preparatorios a la categoría de delito", trad. Fakhouri Gómez, InDret. Revista para el análisis del Derecho, 4, 2010.

RAMSAY, P., The Insecurity State: Vulnerable Autonomy and the Right to Security in the Criminal Law, Oxford University Press, Oxford, 2012.

ROBINSON "Punishing Dangerousness: Cloaking Preventive Detention as Criminal Justice", 114 Harvard Law Review, 2001.

ROBINSON, P.H., Principios distributivos del Derecho penal. A quién se debe sancionar y en qué medida, trads. M. Cancio e I. Ortiz de Urbina, Marcial Pons, 2012.

ROBINSON, P.H. y DUBBER, M.D., "The American Model Penal Code: A Brief Overview", New Criminal Law Review, Vol. 10, Number 3, 2007.

RODRÍGUEZ MOURULLO, G., "La punición de los actos preparatorios", Anuario de Derecho Penal y Ciencias Penales, 21-2, 1968.

SILVA SÁNCHEZ, J. M., El nuevo Código penal: cinco cuestiones fundamentales, Bosch, Barcelona, 1997.

SILVA SÁNCHEZ, J.M., "La «intervención» a través de organización, ¿una forma moderna de participación en el delito?", en CANCIO MELIÁ/SILVA SÁNCHEZ, Delitos de organización, B de F., Montevideo - Buenos Aires, 2008.

SILVA SÁNCHEZ, J.M. La expansión del Derecho penal. Aspectos de la Política Criminal en las sociedades postindustrinales, $3^{\text {a }}$ ed., Edisofer-B de F, Montevideo, Buenos Aires. 2011.

VASALLI, G., voz "Quasi-reato", en Enciclopedia del Diritto, XXXVIII, Giuffrè, Milano, 1987.

VIVES ANTÓN, T. S., "Garantías constitucionales y terrorismo", en ALONSO/CUERDA/FERNÁNDEZ (dirs.), 
Terrorismo, sistema penal y derechos fundamentales, Tirant lo Blanch, Valencia, 2018.

VIVES ANTÓN, T.S., "Constitución y medidas de seguridad", en EL MISMO, La libertad como pretexto, Tirant lo Blanch, Valencia, 1995.

VIVES ANTÓN, T.S., "Segundo seminario: nullum crimen sine lege. Comisión por omisión y dogmática penal", en EL MISMO/CUERDA/GÓRRIZ (eds.), Acción significati$v a$, comisión por omisión y dogmática penal, Tirant lo Blanch, Valencia, 2017.

VIVES ANTÓN, T. S., "Garantías constitucionales y terrorismo", en ALONSO/CUERDA/FERNÁNDEZ (dirs.), Terrorismo, sistema penal y derechos fundamentales, Tirant lo Blanch, Valencia, 2018.

VIVES ANTÓN, T.S./CUERDA ARNAU, M.L., "Estado autoritario y adelantamiento de la «línea de defensa penal»", en MAQUEDA/MARTÍN/VENTURA (coords.), Derecho penal para un estado social y democrático de derecho. Estudios en homenaje al profesor Emilio Octavio de Toledo y Ubieto, Universidad Complutense de Madrid, Madrid, 2016.

ZEDNER, L., "Pre-crime and post-criminology?", Theoretical Criminology, Vol. 11 (2), 2007.

ZEDNER, L., "Pre-crime and pre-punishment: a health warning", Criminal Justice Matters, 81: 1, 2010. 